\title{
Article \\ Electric Vehicle Routing, Arc Routing, and Team Orienteering Problems in Sustainable Transportation
}

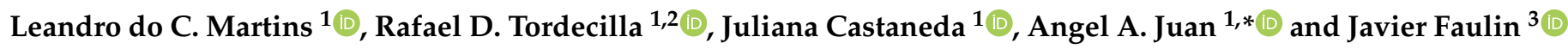 \\ 1 IN3-Computer Science Department, Universitat Oberta de Catalunya, 08018 Barcelona, Spain; \\ leandrocm@uoc.edu (L.d.C.M.); rtordecilla@uoc.edu (R.D.T.); jcastanedaji@uoc.edu (J.C.) \\ 2 School of Engineering, Universidad de La Sabana, Chia 250001, Colombia \\ 3 Institute of Smart Cities, Department Statistics, Computer Sciences, and Mathematics, Public University of \\ Navarre, 31006 Pamplona, Spain, javier.faulin@unavarra.es \\ * Correspondence: ajuanp@uoc.edu
}

check for updates

Citation: Martins, L.C.; Tordecilla, R.D.; Castaneda, J.; Juan, A.A.; Faulin, J. Electric Vehicle Routing, Arc Routing, and Team Orienteering Problems in Sustainable Transportation. Energies 2021, 14, 5131. https://doi.org/10.3390/ en14165131

Academic Editors: Daniel J. Auger and Jorge Barreras

Received: 18 July 2021

Accepted: 17 August 2021

Published: 19 August 2021

Publisher's Note: MDPI stays neutral with regard to jurisdictional claims in published maps and institutional affiliations.

Copyright: (c) 2021 by the authors. Licensee MDPI, Basel, Switzerland. This article is an open access article distributed under the terms and conditions of the Creative Commons Attribution (CC BY) license (https:/ / creativecommons.org/licenses/by/ $4.0 /)$.

\begin{abstract}
The increasing use of electric vehicles in road and air transportation, especially in lastmile delivery and city mobility, raises new operational challenges due to the limited capacity of electric batteries. These limitations impose additional driving range constraints when optimizing the distribution and mobility plans. During the last years, several researchers from the Computer Science, Artificial Intelligence, and Operations Research communities have been developing optimization, simulation, and machine learning approaches that aim at generating efficient and sustainable routing plans for hybrid fleets, including both electric and internal combustion engine vehicles. After contextualizing the relevance of electric vehicles in promoting sustainable transportation practices, this paper reviews the existing work in the field of electric vehicle routing problems. In particular, we focus on articles related to the well-known vehicle routing, arc routing, and team orienteering problems. The review is followed by numerical examples that illustrate the gains that can be obtained by employing optimization methods in the aforementioned field. Finally, several research opportunities are highlighted.
\end{abstract}

Keywords: electric batteries; vehicle routing problem; arc routing problem; team orienteering problem

\section{Introduction}

With the goal of promoting sustainability, many cities in the world are observing an increasing use of electric vehicles (EVs), both for citizens' mobility [1] and for last-mile logistics [2]. The use of zero-emission technologies is supported by governmental plans in regions such as Europe [3], North America [4], and Asia [5]. According to Kapustin and Grushevenko [6], EVs will account for a noticeable share (between $11 \%$ and $28 \%$ ) of the road transportation fleet by 2040. Still, many authors point out batteries' driving range anxiety, high recharging times, scarcity of recharging stations, and lack of effective financial incentives that compensate for the higher cost of most EV models as some of the main barriers for the generalization of EVs in our cities [7-9].

In urban, peri-urban, and metropolitan areas, many activities related to freight transportation and citizens' mobility are carried out by fleets of vehicles [10]. The efficient coordination of these fleets becomes necessary in order to reduce monetary costs, operation times, energy consumption, and environmental/social impacts on the city. However, this coordination constitutes a relevant challenge that is typically modeled as a mathematical optimization problem. Depending on the specific characteristics of the transportation activity, different families of problems can be found in the scientific literature. Among the most popular ones, we can include vehicle routing problems (VRPs) [11-13], arc routing problems (ARPs) [14,15], and team orienteering problems (TOPs) [16,17]. These problems, which can model scenarios involving both road and aerial EVs, are NP-hard even in their 
simplest versions. Thus, the use of heuristic-based algorithms [18] and simulation-based approaches [19] becomes a first-resource tool when solving rich and real-life instances, which usually contain a large number of nodes to be visited. From an operational perspective, the inclusion of driving range constraints and long recharging times constitute additional challenges that must be properly addressed when providing near-optimal transportation plans in any of the aforementioned routing problems (Figure 1).

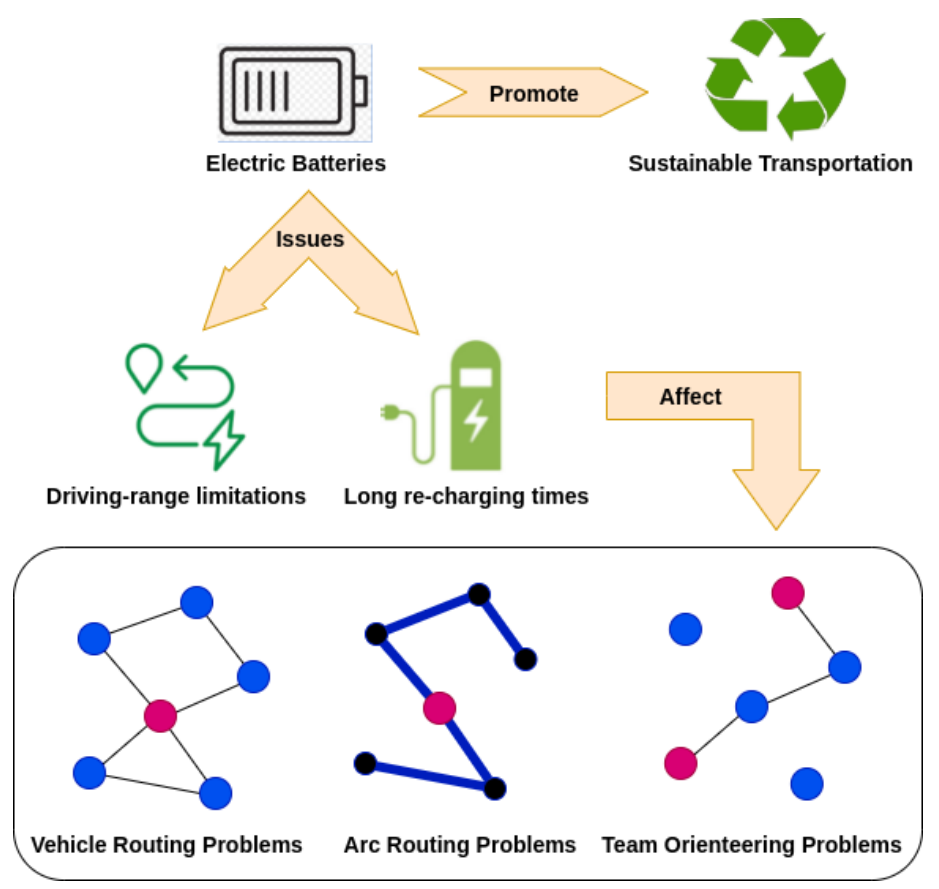

Figure 1. Conceptual schema of the topics discussed in this work.

Among the existing solution approaches for these problems, we highlight the use of exact methods, heuristic and metaheuristic approaches, approximation, machine learning (ML), and simulation techniques. Exact methods guarantee the finding of optimal solutions. However, their use is often limited by the size of instances due to the combinatorial nature of these problems [20]. Conversely, heuristics and metaheuristics have proved to be good alternatives to deal with large-scale problems. These methodologies are capable of finding near-optimal (or even optimal) solutions in a reasonable amount of time [21]. Among the most popular metaheuristic approaches, we highlight the use of evolutionary algorithms, e.g., genetic algorithms (GAs) and non-dominated sorting genetic algorithm (NSGA) [22]; nature-inspired population-based approaches, e.g., ant colony (ACO) [23] and particle swarm optimization (PSO) [24]; and iterative methods, e.g., multi-start (MS) [25], iterated local search (ILS) [26], and variable neighborhood search (VNS) [27]. Approximation techniques, on the other hand, ensure the finding of solutions whose cost is probably within some factor of the optimal solution cost [28]. Apart from efficiently tackling deterministic problems, these solution approaches cannot properly cope with stochastic components. Therefore, simulation methods have been used to deal with stochastic problems, being capable of offering efficient solutions for stochastic scenarios [19]. Furthermore, ML methods make use of existing information, often gathered by the internet of things, i.e., networks of sensors, software, electronic devices, among others, during the execution, in order to automate the decision-making process based on the prediction of possible scenarios (see, e.g., in [29]). Finally, hybrid approaches combine two or more classes of methodologies to enhance the resolution characteristics of each one.

Accordingly, the main contributions of the paper can be summarized as follows: (i) we provide a literature review on different types of electric vehicle routing problems (VRPs, ARPs, and TOPs), highlighting the characteristics of each problem as well as the solution method employed; (ii) we discuss how the sustainable transportation concept relates to 
the increasing use of electric vehicles; (iii) we analyze how the introduction of driving range constraints, associated with the employment of electric batteries, has been taken into account during the development of vehicle routing algorithms; (iv) we highlight the relevance of these range-aware algorithms to avoid increasing the cost of routing plans more than is strictly necessary; and (v) we provide a novel numerical experiment as well as a comparative data analysis of results obtained by different researchers when optimizing routing problems with EVs.

Figure 2 shows the evolution of scientific articles published in Scopus-indexed journals during the last decade. The data has been obtained using the following query: TITLEABS-KEY ("electric vehicle" AND "routing problem") (the value for 2021 is an estimated one, based on the current value at the time this query was performed). One can notice the rapid increase in the number of scientific works analyzing the use of EVs in routing problems. The same query also provide us with information about the journals that have been publishing these papers with a higher frequency (in parentheses): Sustainability (10), Computers and Operations Research (9), European Journal of Operational Research (8), IEEE Transactions on Intelligent Transportation Systems (7), Transportation Research Part B Methodological (6), Transportation Research Part C Emerging Technologies (6), and Transportation Science (6).

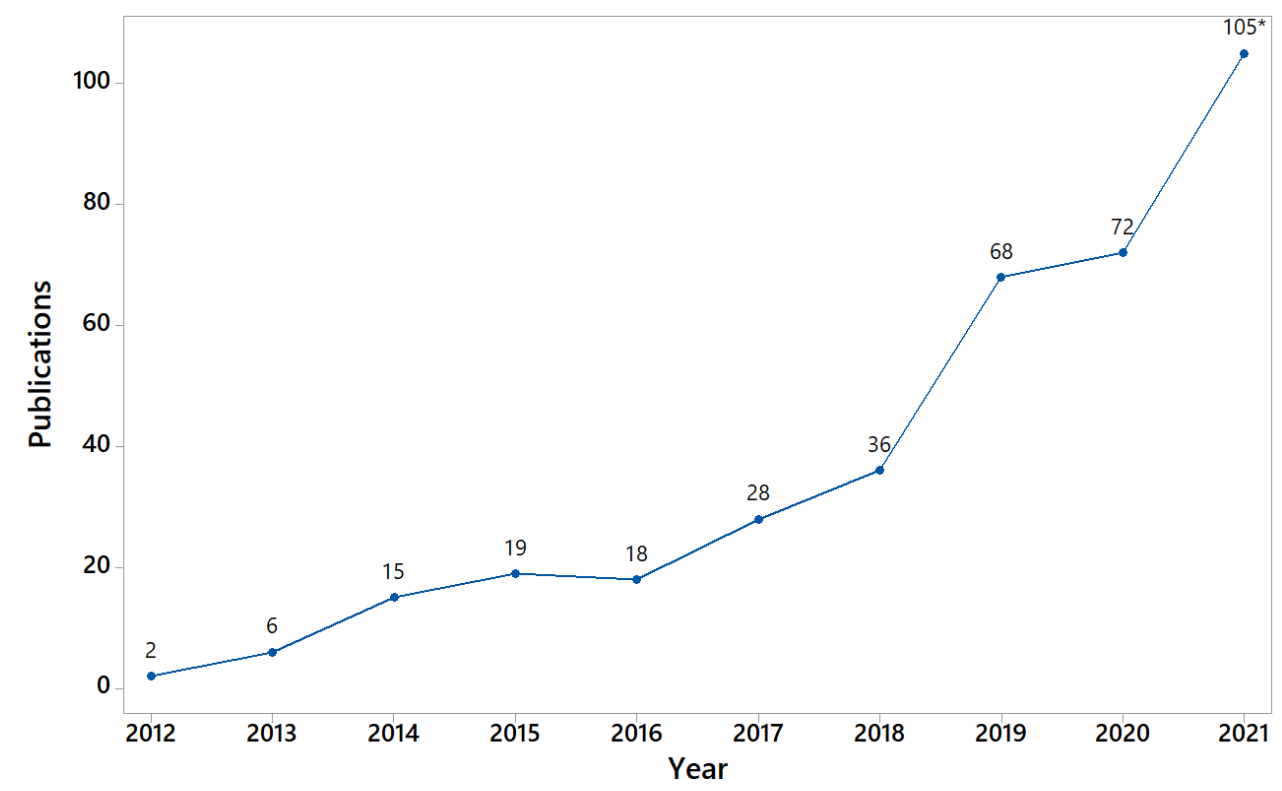

(*) The value for 2021 is an estimate.

Figure 2. Evolution of related publications in Scopus-indexed journals.

The remaining of this paper is organized as follows. Section 2 analyzes the role of EVs in promoting sustainable transportation practices. Section 3 discusses different works on models that estimate remaining driving ranges for EVs. Section 4 summarizes the existing literature on electric vehicle routing problems. Sections 5 and 6 complete a similar review on the electric arc routing and the electric team orienteering problems, respectively. Section 7 illustrates the numerical impact of driving range constraints across different studies. Finally, Section 8 concludes this work by summarizing the main findings and describing some open research lines.

\section{Promoting Sustainable Transportation Practices}

Traditional energy sources employed in mobility and transportation activities also imply the release of undesired byproducts or externalities, including air pollution, noise, roads wear-outs, traffic congestion, and global warming [30]. These contaminant elements are released with the use of vehicles propelled by non-renewable energies with fossil ori- 
gins. Pollutant externalities have a great impact on the environment, forcing governments to either restrict the use of the energy sources that provoke them or to search for new propelling sources. This situation has promoted the concept of sustainable transportation, which McKinnon et al. [31] define as the transportation whose management, use, and development do not compromise or endanger the future development of the next human generations.

One popular way to include externalities in optimization models is by transforming them into penalty costs. This contributes to limit the use of the most pollutant modes of transportation. Nevertheless, estimating these penalty costs is not easy. Measuring the willingness to pay (WTP) of carriers and consumers is one technique that can be employed to estimate the cost of transportation externalities [32,33]. All in all, the goal is to estimate the propensity to use more sustainable modes of transportation in order to avoid higher mobility costs [34,35]. Estimating the environmental costs allows us to consider alternative transportation and mobility strategies [36]. As an example, the work carried out by Lera-López et al. [37] presents a good analysis of the WTP estimations of the road freight transportation that traverses the Pyrenees mountain range, located between France and Spain.

The literature reviews performed by Dekker et al. [38] and Bektaş et al. [39] describe the role of mathematical models in supporting decisions that consider environmental costs in green logistics and green freight transportation, respectively. The concept of the "green corridor" is defined by Panagakos [40] as routes with low pollution impact and good economic and logistics attributes. One of the first mathematical models including environmental costs to solve a transportation problem is shown by Erdoğan and Miller-Hooks [41], who define the green VRP. Previously, Ubeda et al. [42] solved a variant of that model in a case study for a real delivery company in Spain. During the last years, several literature reviews on the green VRP have appeared, e.g., Lin et al. [43], Ren et al. [44], Moghdani et al. [45], Patella et al. [2], and Asghari and Mirzapour Al-e-hashem [46]. Additionally, the consideration of multi-criteria models are particularly useful when environmental costs are included Sawik et al. [47].

The use of horizontal cooperation is becoming progressively popular as a way to promote environmentally friendly transportation practices [48-50]. Similarly, backhauling strategies in distribution activities are showing good upshots in designing real green distribution protocols [51-53]. In particular, crowd-shipping can also be contemplated as a cooperation strategy with positive environmental impacts. Crowd-shipping refers to "the use of ordinary people, rather than delivery companies or company employed drivers, to drop-off packages in route to their destination" [54,55]. The benefits of this cooperation have already been mentioned by McKinnon [56]: a reduction in the demand for urban transportation services, a better achievement of delivery operations, and cheaper distribution trips. Environmental benefits can be increased not only by considering EVs, but also by taking advantage of the solar energy to recharge the batteries. For instance, Lloyd et al. [57] study a real-world case in Tunisia for distributing vaccines. This kind of product requires a cold supply chain [58,59], increasing the need for energy in both the storage and transportation processes. An emerging cooperation strategy relies on the conjoint development of drones and electric vans to increase service quality in urban distribution $[60,61]$.

Regarding urban mobility of citizens, two main policies search for diminishing the damage caused by externalities: (i) managing a large amount of mobility data to reach a smart mobility paradigm, controlling the number of trips and popularizing the shared use of vehicles by means of 5G/6G devices [62], and (ii) promoting a massive use of low environmental impact vehicles, where the electric ones are the best candidates to be chosen [7]. In this context, Roumboutsos et al. [63] propose a methodology to evaluate the introduction of EVs in last-mile logistics. Regarding green freight transportation, Demir et al. [64] offer a review in which different factors of fuel consumption are analyzed. Other strategies have been depicted by Meyer [65], who enumerates a directory of actions to decarbonize 
freight transportation. A conceptual discussion about the shift to EVs in last-mile logistics is provided by Ehrler et al. [66]. These authors address a real-world case in Germany for distributing groceries within an e-commerce context. Mathematical models have also been proposed to evaluate the impact of EVs in last-mile logistics. For instance, MuñozVillamizar et al. [67] evaluate the implementation of EVs in urban freight transportation networks, considering a real-world case in Colombia.

\section{Estimating Remaining Driving Ranges in EVs}

The battery duration of EVs is an issue that concerns both drivers and manufacturers since their origins. Technological development and improvements in the specific energy, specific power, service life, and safety of electric batteries are today the most influential factors for EVs deployment. There are several types of electric batteries developed with different materials and, therefore, with different characteristics and durability [68].

Apart from the driving range offered by batteries, charging times significantly affect the efficiency of EVs. Due to the limited capacity of electric batteries, drivers are forced to formulate driving strategies to optimize stored energy to the maximum, in order to have the required range for the desired travel time [69]. The low availability of public charging infrastructure along most planned routes is one of the main variables influencing the adoption of EVs [70]. Moreover, the availability of charging stations varies from country to country [71]. In the case of unmanned aerial vehicles (UAVs), their flying range has to be carefully planned, as the vehicle's survival might depend on it [72]. As driving ranges show to be a limiting factor in the adoption of EVs [73], electric battery management systems are crucial to their efficient, safe, and reliable operation. One of its main functions is the control of voltage (safety against over-voltage and under-voltage), maximum wind current, temperature, and battery status. Malik et al. [74] identify the main factors that affect the range of electric batteries: gaining vehicle weight with increasing energy density, temperature, cabin air conditioning charge, battery cooling charge, traffic conditions, driving speed, rolling resistance, and air resistance. Several researchers are developing function-monitoring and control strategies based on intelligent algorithms. These serve as the basis for improving the driving ranges of electric batteries, as it is not possible to directly probe their key microscopic physical variables [75]. Lipu et al. [76] present a complete review on the different methods and intelligent algorithms that can be employed to estimate the state of electric batteries. These include regression and probabilistic models, time series analysis, deep learning, fuzzy controllers, etc.

According to Shi et al. [77], knowing the individual battery range generates a better understanding of the environmental benefits associated with a large-scale adoption of EV fleets. These authors develop an optimization model that identifies the minimum required ranges of batteries at the individual level, using a real-world trip and location data for charging stations. Their results indicate that improvements in charging infrastructure can reduce the minimum required range of batteries. Bi et al. [78] estimate the residual range in EVs with the radial basis function neural network. This methodology is tested with historical data taken from operational EVs in Beijing, China. Bi et al. [79] also use real data from EVs in Beijing. They employ a robust nonlinear regression model to predict the remaining driving range under different conditions of temperature, state of charge, and speed. The nonlinear effect of driving speed, acceleration, and temperature on the energy consumption of electric batteries is also confirmed by Fetene et al. [80], who used big data to estimate the energy consumption and driving range of EVs. Their results reveal a $25 \%$ decrease in the driving range during winter, compared to summer, showing that the season and the level of precipitation have a strong effect on energy consumption. Fiori et al. [81] propose one of the most advanced models to calculate energy consumption according to the selected route. They use a real-time global positioning system, together with micro-simulation traffic data.

The estimation of EVs driving range is linked to many factors that make necessary to implement complex algorithms in order to accurately estimate the energy consumption of 
electric batteries [82]. For instance, Neaimeh et al. [83] propose a linear model that uses Dijkstra's graph search algorithm to find the route that minimizes the energy consumption. It aims to extend the driving range of EVs by calculating the minimum energy route to a destination, based on the topography and traffic conditions of the road network. This model is used in the decisions of intelligent navigation and eco-driving assistance systems in EVs. Sautermeister et al. [84] propose driving range estimation taking into account system uncertainties. They use a recursive algorithm with multi-model estimation to include driving endurance parameters in the forecast. These parameters are transferred to a hybrid power train model, which combines the standard longitudinal consumption model with a function approximation for the dynamic driving behavior on a specific route segment. There are also data-driven ML algorithms, which require extensive training and validation procedures to make predictions. Petersen et al. [29] present a methodology for the development and validation of driving range estimation algorithms based on ML approaches. The proposed methodology takes into account the evaluation of driver-specific and non-driver-specific performance. Zhao et al. [85] present a model that combines ML algorithms to predict the remaining driving range. The model is trained on the relationship between driving distance and characteristics such as cumulative engine power output, driving patterns, and battery temperature. Its predictions perform well and have a lower error compared to other models. Similarly, Zheng et al. [86] develop a hybrid ML model to predict the energy consumption of EVs, considering high-dimensional multivariate data and extracting knowledge from historical travel characteristics for other applications. Moreover, Thorgeirsson et al. [87] harness the connection to a back-end of modern vehicles to deploy ML-based driving range estimation software. The system allows accurate range estimation with low latencies, thus improving the experience of EVs users.

\section{Electric Vehicle Routing Problems}

Different fleet alternatives can be found in the literature to reduce greenhouse gas emissions in the VRP [88]. One of these alternatives is the use of EVs, which are characterized as one of the main contributing actors in green logistics [45]. For the transportation industry, EVs represent long-term cost reductions associated with fuel and operations. This is due to their energy efficiency, and despite their relatively low driving range before recharging [89]. VRPs are combinatorial optimization problems that seek to design the optimal routes for a given fleet of vehicles while satisfying customers' demands [46]. EVs are the cleanest possible fleet in terms of carbon dioxide emissions, which has raised the interest of researchers and the concept of electric VRPs (E-VRPs). When solving the VRP, the goal is to design cargo vehicle routes with minimum transportation costs in order to distribute goods between a single depot and a set of customers. Each customer demands a single product from the depot, where a set of capacitated homogeneous vehicles is available. Each vehicle visits a set of customers to meet their demands. Once all customers are serviced, the vehicle returns to the central depot. The objective aims at minimizing the distribution cost, e.g., travel distance or time-based cost, to serve all customers, without exceeding the loading capacity of the vehicles, subject to (i) each route starts and ends at the depot, (ii) each customer must be visited only once and by exactly one vehicle, and (iii) the total demand required by the costumers in a route does not exceed the vehicle's capacity. Figure 3 illustrates a simple E-VRP scenario, with a single depot, several customers whose demands must be satisfied, a maximum loading capacity per vehicle, and traveling costs between any pair of nodes. These problems are characterized by planning routes to deal with electric commercial vehicles in the field of logistics services [45]. Their basic constraints mainly involve the variable amount of energy remaining in the vehicle when arriving at a customer, starting routes with full charge, the location of permitted charging points, and the travel, charging, and service times [46]. 


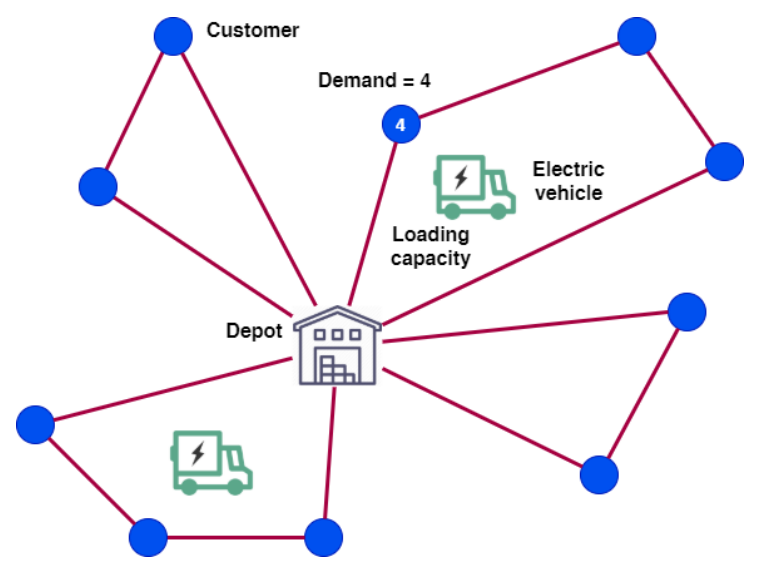

Figure 3. Visual representation of a basic E-VRP.

Conrad and Figliozzi [90] propose one of the first E-VRPs in the literature, where vehicles with limited range recharge at customer locations during the route. Juan et al. [91] introduce the VRP with multiple driving ranges inspired by the constraints of EVs and hybrid-EVs, where the total distance traveled by each vehicle is limited and is not necessarily the same for all of them. These authors propose an integer programming model, and a multi-round heuristic based on a biased-randomized algorithm [92,93]. This algorithm generates solutions to the problem with pre-specified fleet configurations. Furthermore, their results support the hypothesis that hybrid vehicles and EVs can be used in the E-VRP without necessarily incurring significantly high distance-based costs. Likewise, Afroditi et al. [94] formulate a mathematical model for the E-VRP, considering the different constraints associated with the vehicle characteristics and requirements. Schneider et al. [95] develop a solution based on a hybrid heuristic combining a VNS algorithm with a tabu search (TS) heuristic for the E-VRP with time windows and charging stations. Schiffer and Walther [96] solve a similar problem by integrating realistic constraints, such as partial battery charging during routes. Their aim is to minimize route costs with the minimum distance traveled and the lowest possible number of vehicles and charging stations.

Zhou et al. [97] summarizes the most representative articles on E-VRPs variants and heuristic solution methods. Among the exact methods, branch-price-and-cut and branch-and-price algorithms are highlighted. In the heuristic and metaheuristic algorithms, the most widely implemented are savings-based heuristics together with ILS, VNS, and the adaptive large neighborhood search (ALNS) metaheuristic frameworks and GAs. Erdelić and Carić [98] and Asghari and Mirzapour Al-e-hashem [46] also develop an analysis of papers up to 2018 and 2019, respectively. Erdelić and Carić [98] focus on the E-VRP and variants associated with battery EVs, as well as the solution methods. Although Asghari and Mirzapour Al-e-hashem [46] mostly center their work on green VRPs, they also emphasize on E-VRPs and their variants, including a discussion on formulation, solution methods, and applications.

Table 1 summarizes the review of recent Scopus-indexed articles addressing the E-VRP. Within these results, it is possible to find solution proposals for the most general version of the E-VRP, especially with approaches in the urban area. For instance, Li et al. [99] propose a model considering time windows and solve it by employing a mixed algorithm including ACO and GAs. Zhao and Shi [100] focus mostly on the solution method by developing an algorithm based on ALNS to generate efficient initial solutions according to the geographical location and time windows of the customer. It also integrates simulation experiments to prove that the solutions reduce the logistics cost in urban distribution. Similarly, Zhu et al. [101] propose an elitist GA for the E-VRP with time windows in which the scheduled route initiates with a neighbor directionality. They conduct experimental tests on a real simulated case study of a postal company. Outalha et al. [102] propose a model with an adaptive control strategy to manage the routes. They employ timed Petri nets to control the distribution of customers and phase transitions. 
Table 1. Classification of recent papers on the E-VRP according to the problem characteristics and the solution approach.

\begin{tabular}{|c|c|c|c|c|c|c|c|c|c|c|c|c|c|c|}
\hline \multirow[b]{2}{*}{ Authors } & \multicolumn{7}{|c|}{ Problem Characteristics } & \multicolumn{7}{|c|}{ Solution Approach } \\
\hline & $\begin{array}{l}\text { Single } \\
\text { Vehicle }\end{array}$ & $\begin{array}{l}\text { Multiple } \\
\text { Vehicles }\end{array}$ & $\begin{array}{c}\text { Time } \\
\text { Windows }\end{array}$ & $\begin{array}{c}\text { Homog. } \\
\text { Fleet }\end{array}$ & $\begin{array}{c}\text { Heterog. } \\
\text { Fleet }\end{array}$ & Det. & Stoch. & Exact & Heuristic & Metaheuristic & Approximation & $\begin{array}{l}\text { Machine } \\
\text { Learning }\end{array}$ & Simulation & Hybrid \\
\hline Li et al. [103] & - & & & - & & & - & & & $\mathrm{ACO}$ & & & - & \\
\hline Zhang et al. [104] & & - & - & - & & & - & & & ALNS, VND & & & - & \\
\hline Zhen et al. [105] & & - & & - & - & - & & & - & PSO & & & & \\
\hline Keskin et al. [106] & & - & - & - & & & - & & & ALNS & & & - & - \\
\hline Bahrami et al. [107] & & - & & - & - & - & & - & - & & & & & \\
\hline Zhu et al. [108] & & - & & - & & - & & & & SSH-VNS & & & & \\
\hline Kancharla and Ramadurai [109] & & - & & - & & - & & & & ALNS & & & & \\
\hline Mao et al. [110] & & & - & - & & - & & & - & ACO & & & & - \\
\hline Raeesi and Zografos [112] & & - & - & - & & - & & & & LNS & & & & \\
\hline Li et al. [113] & & - & & & - & - & & & & MA, SVND & & & & - \\
\hline Karakatič [114] & & - & - & & & - & & & & GA & & & & \\
\hline Li et al. [115] & & - & & - & & - & & & - & GA & & & & \\
\hline Granada-Echeverri et al. [116] & & - & & - & & - & & & & ILS & & & & \\
\hline Löffler et al. [117] & & - & - & - & & - & & & & LNS, GTS & & & & - \\
\hline Lee [118] & - & & & & & - & & - & & & & & & \\
\hline Al Theeb et al. [119] & & - & & - & & - & & & - & & & & & \\
\hline Zhu et al. [101] & & - & - & - & & - & & & & GA & & & & \\
\hline Lin and Zhou [120] & - & & & - & & - & & & - & & & & & \\
\hline Taş [121] & & - & - & - & & - & & & & & & & & \\
\hline Hulagu and Celikoglu [123] & & - & & $\bullet$ & & - & & - & & & & & & \\
\hline Zhao et al. [124] & & - & - & - & & & - & & & $\mathrm{ACO}$ & & & - & \\
\hline Outalha et al. [102] & - & & & & & - & & - & & & & & & \\
\hline Yang et al. [125] & & - & - & - & & & - & & & & - & & & \\
\hline Bac and Erdem [126] & & - & - & & - & - & & & & VNS, VND & & & & \\
\hline Yu et al. [127] & & - & & & - & & - & & & ALNS & & & & \\
\hline Li et al. [128] & & - & - & & - & - & & - & & & - & & & \\
\hline Yindong et al. [129] & & - & - & - & & - & & & & EDA-LF & & & & \\
\hline Basso et al. [130] & & - & & - & & - & & & & & & - & - & \\
\hline Jia et al. [131] & & - & & - & & - & & & & BACO & & & & \\
\hline Wang et al. [132] & & - & & - & & & - & & & MA & & & & \\
\hline Deng et al. [133] & & - & - & - & & - & & & - & IDE & & & & - \\
\hline Ham and Park [134] & & - & - & - & & - & & - & - & & & & & \\
\hline Florio et al. [135] & & - & & - & & & - & - & & & & - & & \\
\hline Park and Jin [136] & & - & & - & & & - & & - & & & & & \\
\hline Ferro et al. [137] & & - & - & - & & - & & - & & & - & & & \\
\hline Zhao and Shi [100] & & - & - & - & & - & & & & ALNS & & & - & \\
\hline Ge et al. [138] & & - & & - & & & - & - & & & & & & - \\
\hline Wang et al. [139] & & - & - & - & & - & & & & VNS & & & & \\
\hline Li et al. [99] & & - & & - & & - & & & & $\mathrm{ACO}, \mathrm{GA}$ & - & & & \\
\hline Keskin and Çatay [140] & & - & - & - & & - & & - & & ALNS & & & & \\
\hline Verma [141] & & - & - & - & & - & & - & - & GA & & & & \\
\hline
\end{tabular}


The most recent E-VRPs consider different real-life decision variables related to recharging costs, heterogeneous fleet, and the degradation or extension of the battery's lifetime. For instance, Li et al. [128] solve the E-VRP with time windows and mixed fleet by decomposing it according to the Dantzig-Wolfe principle. They also propose both a heuristic and a GA to give an initial solution. Then, the branch-and-price algorithm is used to find the optimal solution. Regarding battery charging management, it is observed that partial or full charging of EVs turns out to be a key differentiation between the best known variants of the problem. Therefore, an E-VRP with time windows and a single recharge is formulated by Löffler et al. [117]. Similarly, an E-VRP with time windows, heterogeneous fleet, and partial charging is solved employing heuristics based on the VNS and the variable neighborhood descent (VND) algorithms [126]. The E-VRP considering realistic energy consumption with partial charging is addressed by Yu et al. [127], who propose an ALNS as the solution method. A time-dependent E-VRP with chance-constraints and partial recharging is tackled by Basso et al. [130] through a probabilistic Bayesian ML approach to predict the energy consumption.

Some recent formulations consider the discharge process as well. For instance, Karakatič [114] proposes an E-VRP with nonlinear charging and load-dependent discharging. Likewise, Zhao and Lu [142] solve a real-life E-VRP with the objective of reducing costs. These authors use a heuristic based on an ALNS framework and integer programming. Eskandarpour et al. [143] also propose a mixed integer linear programming model to minimize the total cost and carbon dioxide emissions of the heterogeneous fleet VRP with multiple loading capacities and driving ranges. They use an enhanced multidirectional local search to approximate the Pareto frontier. Recently, Hatami et al. [144] develop a multi-round iterated greedy metaheuristic to solve a similar problem. These authors provide an efficient solution with different combinations of vehicles in the network and environmental sustainability levels. A comprehensive review of the main variants of the E-VRP with heterogeneous fleet is provided by Hiermann et al. [145].

\subsection{E-VRPs Focusing on Battery Recharge}

Battery management and recharge-oriented models include different variables that are increasingly adapted to the real constraints faced by commercial EVs. Mao et al. [110] propose a hybrid solution combining an ACO algorithm with insertion heuristics and a local search for solving an E-VRP with time windows and considering multiple recharging options. Other variants of the E-VRP include decisions associated with portable charging. Raeesi and Zografos [112] study an on-road charging alternative using two stages. The first stage is for the EVs visiting the customer. The second is for electric vans that require to exchange the depleted battery with a fully charged one. The problem is solved by a twostage hybridization of a dynamic programming algorithm and an integer programming algorithm. The proposed solutions are then enhanced by using a large neighborhood search (LNS) algorithm. Park and Jin [136] model and apply an E-VRP with heterogeneous vehicles and partial charge. They consider different characteristics of vehicles, such as loading capacities, battery capacities, energy consumption rates, and charging speeds. Lee [118] propose a model that considers nonlinear charging times. This model is solved by the branch-and-price method in the extended charging station network.

In addition, Deng et al. [133] propose a more general version of an E-VRP wit time windows and nonlinear loading constraints. This problem is solved employing a hybrid approach that combines an improved differential evolution algorithm and different heuristics. Keskin and Çatay [140] have studied an E-VRP with time-windows, in which partial recharging is allowed and may take place at any battery level. Two cases that benefit from partial recharging, for instance, occur when vehicles visit a station near the end of its route, or when two consecutive recharges are possible, where the full recharging may not be needed. To solve this problem, the authors formulated the problem as a 0-1 MILP and proposed an ALNS to solve it. As a result, the routes could be significantly improved when partial recharging is allowed, even at a predetermined constant level. Similarly, 
Verma [141] have addressed an E-VRPTW. In their case, apart from serving as a recharging station, each station support battery swaps. Therefore, the visiting of an EV to a station can either choose a battery swap or recharge the vehicle battery to its full capacity. To solve this problem, a local search routine combined with GA and improvement heuristics were proposed. They concluded that battery swapping is more efficient in case the swapping time and battery swapping cost are small.

Some recent publications also present E-VRPs variants that consider stochastic variables associated with more realistic scenarios. For instance, Zhang et al. [104] propose a fuzzy E-VRP with time windows and charging stations. Here, uncertainty is modeled by fuzzy simulated numbers for service times, battery energy consumption, and travel times. They also allow partial charging. This creates an initial scenario, from which additional random values are generated. An integrated algorithm, combining an ALNS with a VND, is used as solving approach. Zhao et al. [124] and Zhao and Li [122] propose E-VRPs with time-varying traffic conditions. The goal is to plan the routing of fresh products in the urban cold chain, which is affected by the road type, customer time-windows requirements, freshness of products, and in-route loading queues. An ACO algorithm is used to solve this problem. The results are tested using simulation, showing how this optimization approach allows EVs to effectively avoid traffic congestion during the distribution process, reduce the total distribution cost, and improve the overall performance of the system.

According to Florio et al. [135], EVs route planning must always consider their relatively short autonomy and the effects of traffic congestion on battery consumption. Therefore, they propose a new methodology that serves as a framework for optimization algorithms to solve the E-VRP with stochastic and time-dependent travel times without allowing battery recharging along the way. Granada-Echeverri et al. [116] introduce the E-VRP with backhauls. Furthermore, Yang et al. [125] propose an E-VRP with mixed backward, time windows, and recharge strategies. In order to solve the problem, they decompose it and use the time-dependent forward dynamic programming algorithm to solve it. Similarly, Keskin et al. [106] extend the E-VRP with time windows by considering stochastic waiting times at refueling stations, as these cause disruptions in logistics operations. They employ a two-stage simulation-based heuristic. Initially, waiting times are estimated, while the actual times are simulated and the route is readjusted within the algorithm. This approach provides good-quality solutions, and the uncertainty in waiting times has a positive impact on the routes design.

In E-VRPs with long distances, heuristic approaches are proposed to compute routing and charging point options in heterogeneous networks, as well as the charge level and speeds that optimize them in time. For instance, Cussigh et al. [146] show real-time applicability by providing near-optimal strategies in short computing times. More extensive works, such as that of Desaulniers et al. [147], consider four different variants of E-VRPs with time windows: (i) maximum single full-battery recharge per route, (ii) multiple full-battery recharges per route, (iii) maximum single-battery recharge per route as well as possible partial battery recharges, and (iv) multiple partial recharges. They use exact branch-price-and-cut algorithms based on customized one-way and two-way labeling algorithms that generate feasible routes. Their results show that multiple and partial recharges help to reduce routing costs and the number of employed vehicles. E-VRPs are also used with the objective of finding an optimal and adaptive routing and charging policy. Taş [121] proposes an E-VRP with flexible time windows, in which vehicles can serve customers before and after the time windows limits. This model is solved by a column generation algorithm. Regarding the policies for charging stations, the approach developed by Sweda et al. [148] considers them as the nodes in the network with a certain probability of being available. Froger et al. [149] propose an E-VRP with a nonlinear charging function, considering the limit of available charges of stations as a constraint. They solve it with a route-first-assembly-second metaheuristic. Montoya et al. [150] also solve this problem with a hybrid metaheuristic that combines an ILS and a concentration heuristic. Their results allow them to state that the battery charge level is a nonlinear function of the charging 
time, and not considering it generates unfeasible and costly solutions. Kancharla and Ramadurai [109] propose a more realistic extension by taking into account load-dependent discharge and nonlinear charging in the E-VRP. They assume that the heaviest load should be delivered first, thus extending the battery charge duration. They use a modified ALNS algorithm with removal and insertion operators. Recently, Lin and Zhou [120] investigate the effects of different factors (service area, number of customers, battery capacity, number of charging stations, vehicle capacity, and charging rate) on electric trucks. They use a local search heuristic to solve this problem, which is modeled as a single-depot green E-VRP including both pickup and delivery actions.

\subsection{E-VRPs Focusing on Customers' Demands}

Customers' demands also play an important role in terms of stochasticity and dynamism within the E-VRP formulation. For instance, Ge et al. [138] propose an E-VRP with stochastic demands and proactive corrective measures. They develop a model with probability constraints that is solved by a hybrid heuristic algorithm combining a sparing method and an improved TS algorithm. Similarly, in the context of delivering products directly from the manufacturing plant to the end customers, Al Theeb et al. [119] propose a constructive heuristic and an exact method for the E-VRP. Their objectives are both ensuring routes optimality and customer satisfaction. The results of both solution methods are competitive in terms of computational times and quality. Given the complexity of considering both customers' demands and EVs charging, Jia et al. [131] develop an E-VRP with capacity constraints that is solved in two stages. In the first stage, they do not consider EVs charging and prioritize customer satisfaction using an ACO algorithm. In the second stage, they design a heuristic that satisfies the electrical requirements of the grid. In passenger transportation E-VRPs, Hulagu and Celikoglu [123] consider explicitly intermediate nodes, as well as time-varying passengers' demands at bus stops, vehicle dynamics, battery characteristics, and recharging times. Wang et al. [132] propose a dynamic E-VRP in which the customers' demands may change over time. They propose an adaptive memetic (AM) algorithm to solve this problem, in which they use an evolutionary algorithm to obtain efficient solutions. The authors of [108] propose an E-VRP which considers multiple depots with capacity constraints, and where the customers' demands are composed of two-dimensional weighted items. This problem is solved by a hybrid metaheuristic that combines a VNS algorithm and the space-saving heuristic.

\subsection{E-VRPs Focusing on Carbon Emissions and Hybrid Fleets}

Minimization of $\mathrm{CO}_{2}$ emissions has also been a topic of interest in several E-VRP articles. For instance, Li et al. [103] include the environmental cost related to carbon taxes in the objective function. These authors optimize the model by employing an ACO algorithm. They also perform simulations considering different realistic scenarios, where electricity prices vary over time and carbon prices are taken into account. Zero-emission technologies have also been employed in multi-echelon distribution systems. In the same direction, Li et al. [115] study a variant of the E-VRP that considers constraint on both battery life and battery swapping stations. They use an adaptive GA based on scaling optimization and neighborhood search to optimize energy costs as well as travel times. Computational results indicate that optimal management of energy consumption and travel times reduce both carbon emissions and total logistics delivery costs. A novel formulation for a twoechelon capacitated E-VRP with time windows and partial recharging is proposed by Caggiani et al. [151]. In this system, while electric vans are employed for delivering goods from the depot to satellites, electric cargo bikes are utilized in the last-mile delivery. A set of dummy stations is available, and several visits are allowed at each recharging station. The problem is formulated as a mixed-integer linear programming model and solved with the commercial CPLEX solver.

Hybrid fleets of vehicles are an intermediate point in the transition to fully sustainable fleets for some transportation sectors. They have the ability to switch between the 
use of fossil fuels and electric power. For this reason, several E-VRPs also focus on the combination of gasoline and electric powered vehicles. Therefore, Zhen et al. [105] use a PSO algorithm to minimize energy consumption in hybrid fleets of vehicles. In a similar way, Bahrami et al. [107] propose a model that manages the utilization of different energy sources. This model is solved through an exact branch-and-price method and a heuristic routing-first-distribution-later algorithm. Li et al. [113] also addresses a similar problem by combining a memetic algorithm with a VND.

\section{Electric Arc Routing Problems}

The electric arc routing problem (E-ARP) is a variation of the classic ARP in which electric vehicles are employed to perform the routes. The classic ARP is defined on an undirected graph, in which a subset of edges (requesting edges) has a positive demand that must be satisfied by a set of capacitated homogeneous vehicles. The rest of the edges (traversing edges) are assumed to have a null demand, thus visiting these edges is not mandatory, but they can be freely traversed by the available vehicles. Figure 4 shows a simple example of an E-ARP with these characteristics. Therefore, the E-ARP consists in designing a set of routes that satisfy the demands of all requesting edges, with the objective of minimizing total costs. These costs can be defined in terms of expenses, traveled distance, or time. Each route is traversed by only one capacitated electric vehicle that departs and returns to the same single depot. This return can be performed either using the same edges employed in the outward journey or different ones. The sum of the demands of all requesting edges in each route must not exceed the capacity of the assigned vehicle. Each edge with positive demand is serviced exactly once. Additionally, electric vehicles have a limited driving range-usually measured in terms of time or distance-that must be respected.

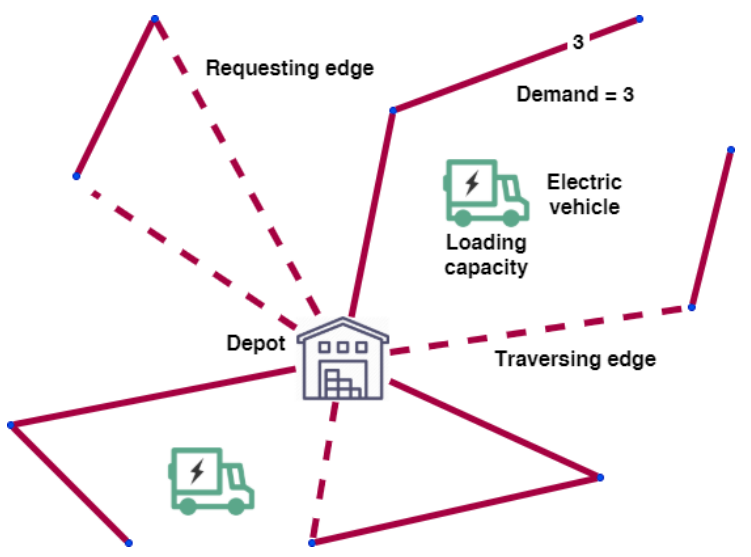

Figure 4. Visual representation of a basic E-ARP.

Most articles on the E-ARP refer to the employment of unmanned aerial vehicles (UAVs), also known as drones, in multiple applications. One paper that does not consider UAVs is the one by Yurtseven and Gökçe [152]. This paper uses mixed integer programming to model an ARP related to the use of electric-powered street sweepers. The goal is to minimize the energy consumption of vehicles. Multiple sets of small instances, based on a real case in the city of Izmir (Turkey), are solved optimally. Different levels of demands and time windows are analyzed. Table 2 classifies recent E-ARP articles according to the following dimensions: (i) the characteristics of the addressed problem and (ii) the solving approach employed. Regarding the first dimension, the analyzed papers can consider either one or multiple periods to design the routes. All available vehicles can either have the same capacity (homogeneous fleet) or different capacity (heterogeneous fleet). Additionally, the parameters and variables can either be uncertain (stochastic problem) or not (deterministic problem). Only Yurtseven and Gökçe [152] consider time windows. Regarding the second dimension, pure exact and heuristic approaches are the 
most used methods, with the exception of Campbell et al. [153], who employ a combined matheuristic approach.

Table 2. Classification of the revised E-ARP papers according to the problem characteristics and the solution approach.

\begin{tabular}{|c|c|c|c|c|c|c|c|c|c|}
\hline \multirow[b]{2}{*}{ Authors } & \multicolumn{7}{|c|}{ Problem Characteristics } & \multicolumn{2}{|c|}{ Solution Approach } \\
\hline & $\begin{array}{l}\text { Single } \\
\text { Period }\end{array}$ & $\begin{array}{l}\text { Multiple } \\
\text { Periods }\end{array}$ & $\begin{array}{c}\text { Time } \\
\text { Windows }\end{array}$ & $\begin{array}{c}\text { Homog. } \\
\text { Fleet }\end{array}$ & $\begin{array}{l}\text { Heterog. } \\
\text { Fleet }\end{array}$ & Det. & Stoch. & $\begin{array}{c}\text { Exact } \\
\text { Method }\end{array}$ & Heuristic Matheuristic \\
\hline Yurtseven and Gökçe [152] & $\bullet$ & & $\bullet$ & & $\bullet$ & $\bullet$ & & $\bullet$ & \\
\hline Campbell et al. [153] & $\bullet$ & & & $\bullet$ & & $\bullet$ & & $\bullet$ & $\bullet$ \\
\hline Campbell et al. [154] & $\bullet$ & & & $\bullet$ & & $\bullet$ & & & $\bullet$ \\
\hline Chow [155] & & $\bullet$ & & $\bullet$ & & & $\bullet$ & $\bullet$ & \\
\hline Li et al. [156] & & $\bullet$ & & & $\bullet$ & & $\bullet$ & $\bullet$ & $\bullet$ \\
\hline Liu et al. [157] & $\bullet$ & & & $\bullet$ & & $\bullet$ & & & $\bullet$ \\
\hline Luo et al. [158] & $\bullet$ & & & $\bullet$ & & $\bullet$ & & & $\bullet$ \\
\hline
\end{tabular}

Poikonen and Campbell [159] highlight that UAVs not only can be used in scenarios where they show advantages over other alternatives, but also that their flying capabilities enable their use in completely new applications. Poikonen and Campbell [159] outline some application areas of drone routing, such as goods delivery, surveillance, agriculture, healthcare, and infrastructure inspection (e.g., inspection of power lines, pipelines, and railroads). Additionally, Campbell et al. [154] cite applications in traffic monitoring, as well as others regarding three-dimensional arc routing problems, such as the inspection of wind turbines and undersea infrastructure.

In general, UAVs can be powered by either fuel or batteries. Despite the utilization of fuel is explicit in this research, cost and capacity parameters can be easily extended to the battery-powered case. For instance, the vehicle fuel capacity affects the drone flight time in a similar manner as a battery endurance does. Donateo et al. [160] perform a comparison between a hydrogen fuel cell and different types of lithium batteries, in terms of the UAV endurance. Their experiments show a superiority in performance of batteries over fuel. However, Fotouhi et al. [161] state that employing drones powered by gasoline allows for longer flight times. Different drone characteristics are analyzed by these authors as well as Mozaffari et al. [162].

UAVs can directly travel from a vertex to any other vertex, without the limitations of existing roads. This characteristics is analyzed by Campbell et al. [154], who study a set of drone ARPs. Additionally, UAVs may start and end the service of an edge at any point. For instance, the UAV can initially serve a part of the edge, then serve another edge, and finally return to the first edge to serve the rest of it. This assumption makes the drone ARP a continuous optimization problem. Therefore, authors approximate the edges as polygonal chains in order to solve a discrete optimization problem. The opportunity of employing approximate methods, such as metaheuristics for deterministic E-ARPs [163] and simheuristics for stochastic E-ARPs [164], remains open for future research. Campbell et al. [154] study a set of randomly generated instances, where a single drone with unlimited driving range is consider. Then, a more realistic case is analyzed by assuming limited riving ranges. This forces to employ a fleet of drones. The discussion about the latter case is extended in Campbell et al. [153]. The edges approximation through polygonal chains is also considered. Two methods are proposed to solve this problem. First, a mixedinteger linear model is formulated and solved through a branch-and-cut algorithm. Second, a matheuristic based on splitting edges, local search, and optimization procedures is proposed.

Real-world cases considering drone E-ARPs have also been studied. For instance, Li et al. [156] address a traffic monitoring problem in Shanghai (China). They formulate a mixed integer programming model that combines the ARP and the inventory routing problem. The inventory consideration is useful to study dynamically traffic monitoring. In this problem, taking into account multiple periods becomes relevant, as the service level demand of each arc in each period depends strongly on previous periods' events, e.g., a 
traffic accident. Given the limited battery capacity, a set of UAVs is necessary to perform efficiently the monitoring tasks. A local branching-based heuristic is proposed to solve the problem.

Designed routes can be traveled as well by employing simultaneously a ground vehicle and a drone, so that the UAV covers larger areas. In this case, the ground vehicle transports the drone to a known location, where the drone is launched to perform the scheduled task along the edges. Later, the ground vehicle retrieves the drone in a different point of the network to recharge or replace its battery before re-launching it. This process is repeated until the demand of all edges in the network has been met. A procedure with these characteristics requires a double-layer routing problem, i.e., each vehicle travels using its own network, and both networks have common nodes to perform the battery recharging task. The ground vehicle travels using existing roads according to a traditional routing problem, while the UAV travels following power lines, pipelines, streets, or any other element requiring attention. For instance, a two-layer E-ARP for the inspection of highvoltage power transmission lines is proposed by Liu et al. [157]. The inspection system is composed of a ground vehicle and a drone equipped with airborne sensors. Two heuristics based on cluster-first-route-second, route-first-split-second, and local search procedures are proposed to solve the problem. A similar problem is tackled by Luo et al. [158], who study traffic patrolling activities with drones in urban areas. This problem is modeled as a double-layer E-ARP, as the drone is transported by a patrol vehicle, which also perform mission visits. Therefore, the vehicle retrieves the drone before its battery is depleted. A mixed integer programming model is proposed, and a two-stage heuristic algorithm is designed to solve the problem. A set of benchmark instances and a real-world case in the city of Hefei (China) are employed to test the algorithm performance.

\section{Electric Team Orienteering Problems}

Unlike VRPs, visiting all customers in a TOP is not mandatory. Frequent situations in which this particularity lies occurs due to the restrictions on the fleet size and the maximum length that any route can cover. In a typical TOP, each customer offers a reward to be collected, which is gathered the first time it is visited. In this way, solving the TOP aims at maximizing the total reward gathered by a fixed fleet of vehicles when visiting a set of customers. In other words, vehicles depart from an origin node (start depot), visit a set of customers, and move towards the destination node (end depot). Differently from the VRP, cargo constraints are usually not considered in the basic version of the TOP. In the case of employing EVs, the operation of each route is constrained due to their limited driving range. As a consequence, it is typically the case that not all customers can be visited. Figure 5 shows a representation of a basic electric team orienteering problem (E-TOP), with an origin depot, a destination depot, a distance or time threshold per route, some customers who are visited to collect the associated rewards, and some other customers who are skipped due to the fleet and time/distance limitations.

The TOP was first introduced in the literature by Chao et al. [165]. The use of UAVs in cargo transportation by parcel delivery companies has gained attention over the years, and consequently, this new mode of transportation has been also employed in TOP systems. Apart from being restricted in load capacity, UAVs are also limited by the driving range due to the use of batteries. Particularly, the latter requires efficient planning operation for such vehicles, as undesirable and usually expensive route failures can occur [166]. Consequently, new challenges have arisen, such as additional decisions about where and when to recharge the batteries, which is not only related to the use of UAVs but also with every type of EV [167]. 


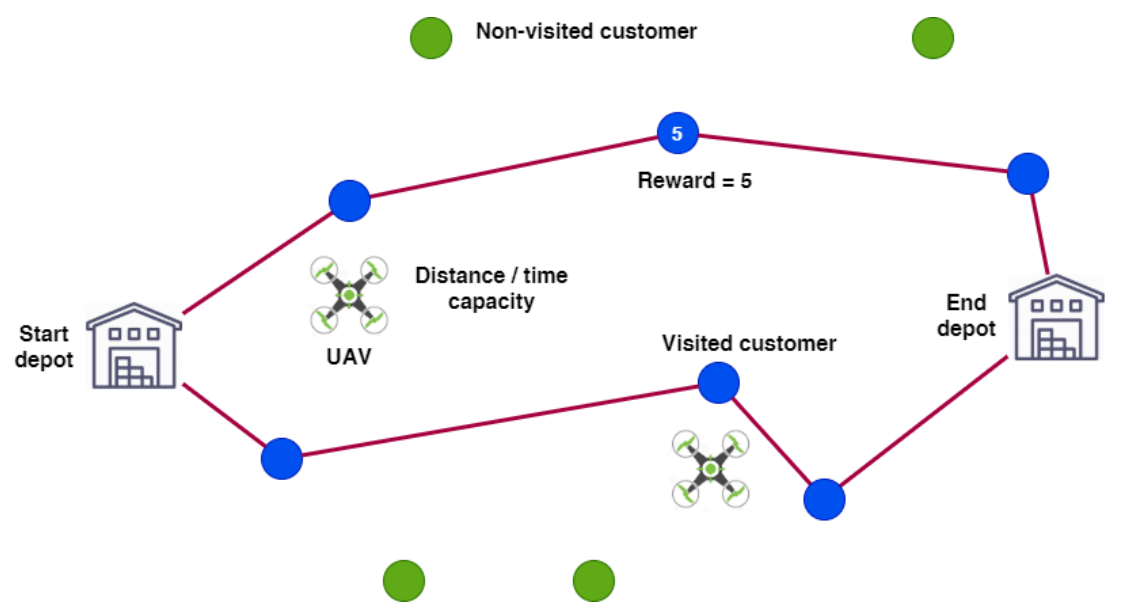

Figure 5. Visual representation of a basic E-TOP.

\subsection{Orienteering Problems with Multiple Vehicles}

UAVs have been primarily used in military missions, where their use goes from goods delivery (e.g., weapons) to surveillance (e.g., to gather intelligence). In the latter, UAVs are equipped with sensors for gathering intelligence information from a set of known targets. Mufalli et al. [168] address a TOP to optimally assign sensors to UAVs and route them through a target field to maximize intelligence gain. A single base (the depot) is available, from where the UAVs must depart, survey a set of targets, and return to. The travel time is limited by the driving range of the UAVs. The authors have considered that, by collecting sensors, the driving range of the UAVs is reduced by the weight which has been added. To solve this simultaneous sensor selection and UAVs routing, the authors propose both an exact mathematical programming model and three local search-based heuristics. The model is solved using the CPLEX commercial solver. However, it is limited to solve small-sized missions. Larger missions are solved employing heuristics, which are enhanced by column generation.

Apart from using UAVs for surveillance purposes in TOP systems, these vehicles have been also considered in the context of smart cities. In this case, UAVs aim at delivering goods in a space that is shared by different types of operations, vehicles, and users. ReyesRubiano et al. [166] studied a TOP in which a set of UAVs must visit a series of customers without violating a driving-range constraint. In their case, the rewarding quantity implied that visiting a customer is modeled as a random variable, which results in a stochastic TOP. Moreover, instead of considering a fixed service time when visiting each customer, this time depends on the collected reward, i.e., a higher reward is more likely to require more time to perform the collection. Consequently, feasibility issues can occur as more time than estimated for the battery might be necessary for completing the routes. A simheuristic algorithm [19] is proposed to cope with this problem. In conclusion, they assert that solutions for the deterministic TOP should not be used in the stochastic version, since they become suboptimal under uncertainty scenarios. Likewise, Panadero et al. [169] have studied a stochastic TOP, in which the uncertainty not only refers to the collected reward, but also to the adoption of random travel times. Although travel times in real-life are completely stochastic due to externalities that vary from traffic to weather conditions, the deterministic versions of TOP are still the most studied in the literature. Hence, by considering stochastic travel times in their model, the authors provide decision-makers with additional information regarding the probability of UAVs violating the driving range threshold due to unexpected events, thus avoiding the collected rewards from being lost because of route failures. A simheuristic algorithm is proposed to solve this problem. In their case, a VNS is combined with Monte Carlo simulation. The solutions returned by the simheuristic approach offer better and more reliable performance under the presence of uncertainty. 
In Juan et al. [170], the dynamic conditions of smart city environments are jointly addressed in a TOP system. Therefore, dealing with them requires the solving methodology to be able to react to these changes in real-time. In order to solve the TOP and provide solutions in real-time, an "agile optimization" strategy is proposed, which combines a biasedrandomized version of a fast constructive heuristic with parallel computing [171,172]. On average, the optimal solution was found for the majority of instances in less than one second. Bayliss et al. [16] propose a learnheuristic to solve the TOP, in which travel times between targets are realistic by considering associated physical constraints, such as air resistance, scent angle, gravity, and speed reduction caused by turning. This learnheuristic combines the use of a metaheuristic with ML, being the latter mainly responsible for predicting these realistic travel times [173]. Similarly, Saeedvand et al. [174] propose a hybrid solution method that combines an evolutionary multi-objective approach with a learning algorithm to solve a TOP with time windows for rescue operations. In this case, the fleet is composed of humanoid robots which aim at optimizing five different objectives: task rewards, task completion time, total energy, maximum energy consumption for a single robot, and missed deadline penalties. Each robot serves a route by performing a set of tasks, which generates a profit whenever a task is visited within its time window. Similar to previous examples, the energy of each robot is limited, which implies that the allocated tasks must be concluded before it is over. They address both static and dynamic environments, in which the static scenario is very optimistic as the nature of rescue applications is completely dynamic. In this way, the learning algorithm aims at updating robots' plans to make proper online fast decisions in the global perspective.

A different application of EVs in TOP systems is presented by $\mathrm{Xu}$ et al. [175]. Here, energy-critical sensors are geographically distributed, and they need to be charged by mobile chargers. These mobile chargers have pre-defined limited energy capacities, which may not be enough to charge all the sensors, thus limiting the visiting of all sensors from the network. Apart from considering the edge-travel cost, an additional cost is set to each node as the mobile charger also consumes energy when charging a sensor. Different vehicle types are considered, which depends on their battery and, consequently, their flying range. Moreover, a sensor can be visited by different vehicles, then incurring less marginal profit. To solve the problem, an approximation algorithm is proposed, which is subsequently enhanced to cope with the case in which the vehicles are of the same type.

Recently, a concurrent multi-threaded branch-and-price algorithm with acceleration schemes was proposed by Sundar and Sanjeevi [176] to solve a TOP. In this case, fixed-wing drones were considered, whose employment brought additional constraints to the problem. Among them, kinematic constraints that prevent them from making on-the-spot turns, then restricting to a minimum turn radius. For this reason, the assumption that the minimum distance between two points is equal to the Euclidean distance is invalidated. In turn, the minimum distance becomes dependent on both the angle of departure and angle of arrival, whose information becomes part of the decision-making process. Branching techniques are proposed to cope with these constraints. The authors have tested their approach on instances composed of up to 65 targets, with a maximum running time of one hour. The approach was able to find optimal solutions for most problem instances. However, the use of exact approaches, such as those proposed in this study, limits finding solutions in real-time, which is a requirement in many dynamic systems.

\subsection{Orienteering Problems with a Single Vehicle}

The single-vehicle orienteering problem (OP) has been used as a basis for different problems, such as the tourist trip design problem [177]. In this case, tourists must select, from a set of points of interest, the most important attractions they desire to visit [178]. When considering EVs as part of this trip planning process, the limitation of the driving range of batteries should be taken into account in order to allow tourists to continue their trip without incurring in long waiting times. A seminal study that addresses EVs in OPs is presented by Lee and Park [179]. In their case, the OP is modeled as a tour planning 
service, in which a maximal number of spots are selected to be visited. To solve this OP, a GA is proposed. The waiting time denotes the time interval in which the tourists wait for their vehicles to be charged without doing anything. They assume that every spot has a charging facility. As expected, employing EVs in these systems is limited not only by their battery capacity, but also by the existence of charging stations. From the experiments, the authors conclude that $95 \%$ of the selected spots could be visited without generating waiting times for tourists. A tour recommendation scheme for EVs is also proposed by Lee et al. [180]. Their goal is to minimize the time waste induced by long charging times. Differently from the previous work, this system combines the traveling salesman problem and the OP. While the spot selected by the tourists should be included in the final tour plan, the recommendable places do not need to be mandatorily included. Similar to Lee and Park [179], a GA is proposed to solve this rich OP, which was able to reduce waiting times in up to $67 \%$.

Wang et al. [181] consider an EV tour planning with time windows. These authors introduce EV recharging logic constraints, which allow them to obtain the battery's state at each node. Consequently, they can check whether the next part of the trip is feasible or not. Heuristic-based approaches are proposed to solve this problem by considering problem reduction techniques. Each reduced problem is solved by an exact algorithm by simultaneously examining the score of a location and the time to reach it. The heuristics were tested on the road network of Penghu Island (Taiwan). Another EV tour planning with time windows has been studied by Chen et al. [182] in order to maximize profitability and minimize energy anxiety within a planning horizon. Range anxiety of drivers is known as one of the main barriers to promote the use of EVs. In contrast to Lee and Park [179], in this work recharging nodes are not simultaneously attraction nodes. They consider both the full- and partial-recharge policies. To solve this challenge, they formulated it as a bi-objective nonlinear programming model and solved it with an interactive branchand-bound algorithm based on non-dominance sets. The proposed approach was able to obtain optimal solutions for different recharging policies. A multi-stage tourist trip design problem is addressed in Karbowska-Chilinska and Chociej [178]. Unlike previous works, this study considers a tour that is composed of more than one connected trip, i.e., a multi-stage strategy. Therefore, it is possible to consider this set of connected trips as a "team" of trips, which leads to a TOP. The vehicles are assumed to start the trips with fully charged batteries. To solve this problem, the authors also propose a GA that was tested on a realistic database composed of 303 nodes and 21 charging stations, in the Poland Silesian region. When compared with a greedy approach, the GA was able to generate more attractive routes to tourists in shorter execution times.

Similar to the study presented by Mufalli et al. [168] in the context of surveillance operations, Pěnička et al. [183] analyze an OP employing a drone for data collection missions. This variant considers that the data (i.e., the reward) may be collected from a close neighborhood sensing distance around the target locations. A VNS metaheuristic is proposed to solve this problem.

Table 3 summarizes the revised papers. These works were classified according to the following characteristics: the consideration of either single or multiple vehicles in the fleet, the inclusion of time windows for visiting corresponding locations, the employment of either homogeneous or heterogeneous fleet of vehicles, and the problem formulation as deterministic or stochastic. Regarding the proposed solution approaches, they are categorized into exact methods, heuristics, metaheuristics, approximation methods, ML, simulation, and hybrid approaches. As we can see, only a few studies in the literature address the stochastic variant of the TOP with EVs. Regarding the solving approaches proposed to cope with these problems, most studies make use of heuristics and metaheuristics methods. For the latter, we highlight the use of evolutionary algorithms, as well as VNS and MS approaches. Some hybrid methodologies have been also proposed, e.g., simheuristics [169] and learnheuristics [16]. 
Table 3. Classification of the revised E-TOP papers according to the problem characteristics and the solution approach.

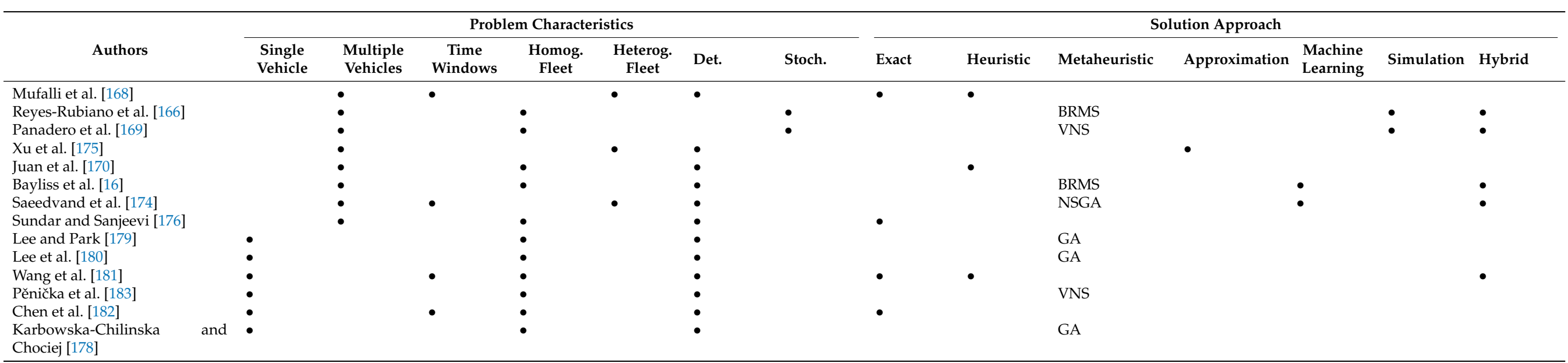


With the emergence of sustainable transportation practices, the employment of EVs in OPs and TOPs has resulted in many operational challenges. Most of the aforementioned studies consider the driving range limitations imposed by the use of electric batteries. In the case of UAVs, one should consider the impact of the load weight on the driving range. As pointed out by Wang et al. [181], the future development of EVs depends not only on increasing the vehicle range and speed, but also on improving their recharging efficiency.

\section{Some Numerical Examples}

This section describes three numerical examples that illustrate the concepts discussed in the previous sections. The first two analyses make use of data extracted from previous works on these topics, while the last one relies on completely new experiments.

The first experiment is based on data provided by Eskandarpour et al. [143] and Hatami et al. [144]. Our analysis aims at investigating the expected environmental impact-in terms of the saved amount of $\mathrm{CO}_{2}$ emissions-when combining three different types of vehicles: small-sized (S) EVs, medium-sized (M) hybrid vehicles, and large-sized (L) combustion engine vehicles. Figure 6 depicts how the environmental impact reacts according to the changes in the type of vehicles that composes the fleet. Each set of three points (vertically) represents the results obtained for a single instance in terms of both the environmental impact and the distribution of the vehicle types in the corresponding fleet. Therefore, each point represents the percentage of its type of vehicle for a given environmental impact. For example, for the problem instance with an environmental impact of 53 , we require a fleet with $84 \%$ of large vehicles, $3 \%$ of medium vehicles, and $14 \%$ of small vehicles. When analyzing Figure 6, we can notice how the use of EVs has an impact on the environmental aspect of these transportation systems. We can analyze both extreme cases, in which the environmental impact goes from 53 to 88 . The lowest case addresses the use of only $14 \%$ of the fleet to EVs. Consequently, this solution does not provide efficient planning operations in terms of environmental cost. On the contrary, the last solution employs $49 \%$ of EVs in its fleet, which results in a greener solution. Regarding the remaining data, it can be seen through the trend line that the higher the number of EVs employed, the higher the achieved environmental impact, and vice versa.

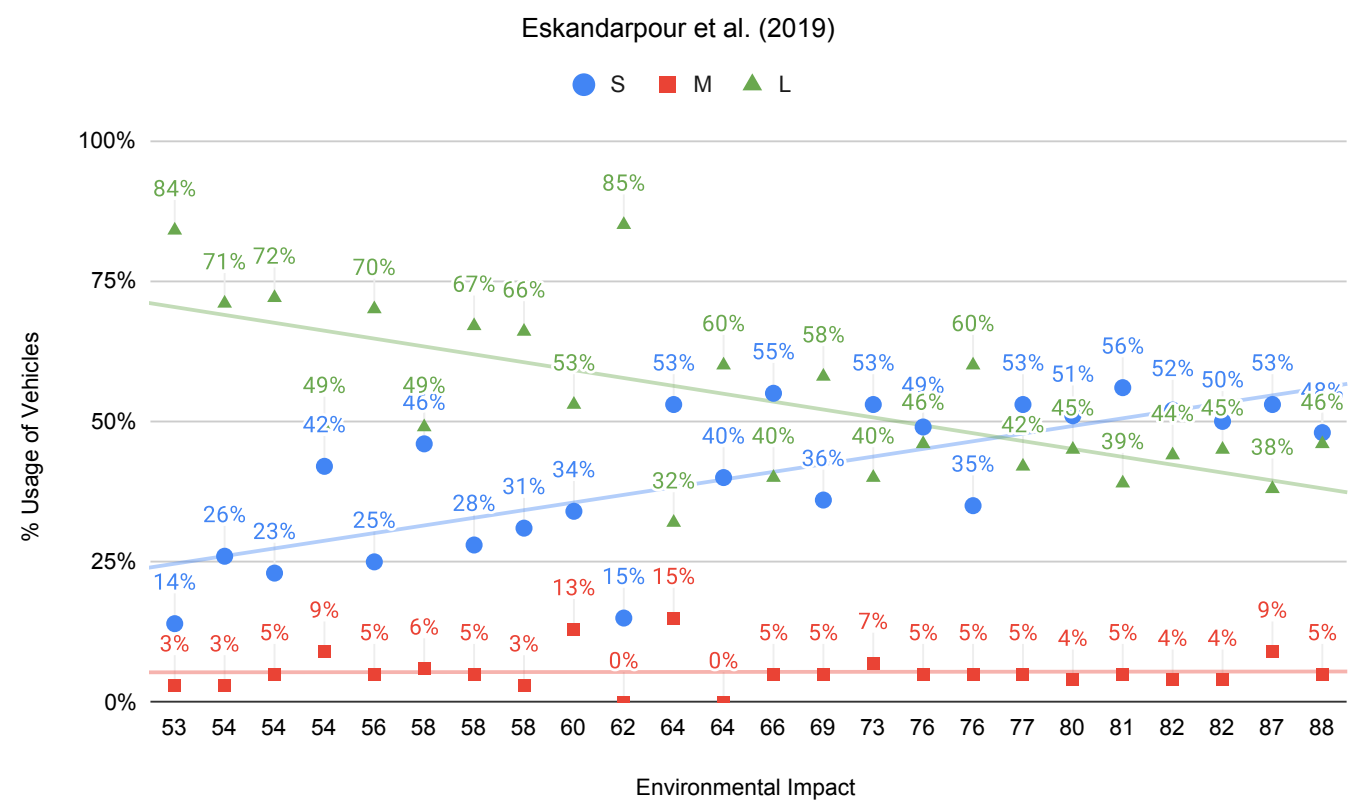

Figure 6. The expected environmental impact according to the percentage usage of each vehicle type of the fleet. 
Figure 7 displays the trade-off between the economical and environmental aspects of two different VRP solutions. For each solution, four different fleet schemes are represented by the 3-tuple (S, M, L), which addresses the percentage of small-, medium-, and large-sized EVs, respectively, in these solutions. Noticeably, the solutions with higher environmental impact require a higher operating cost, due to the use of more EVs (e.g., solutions with $79 \%$ or $42 \%$ usage of EVs). In contrast, solutions with cheaper costs employ larger vehicles, which also implies higher environmental costs (e.g., solutions from 83\% of large vehicles). Therefore, considering a balance between the fleet size is a key factor in order to ensure both economical and environmental efficiency of these fleets.

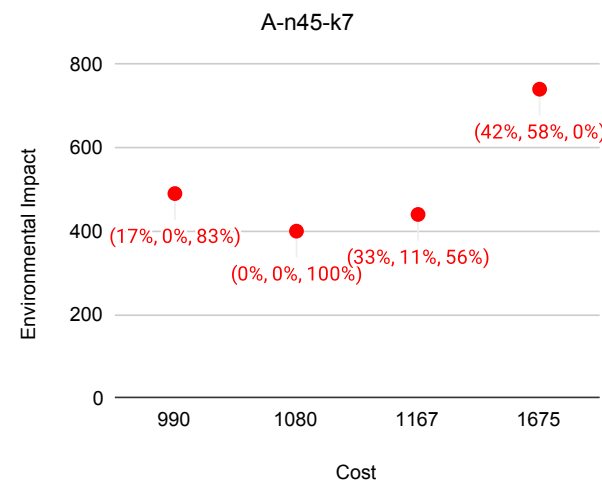

(a) Instance composed of 65 nodes.

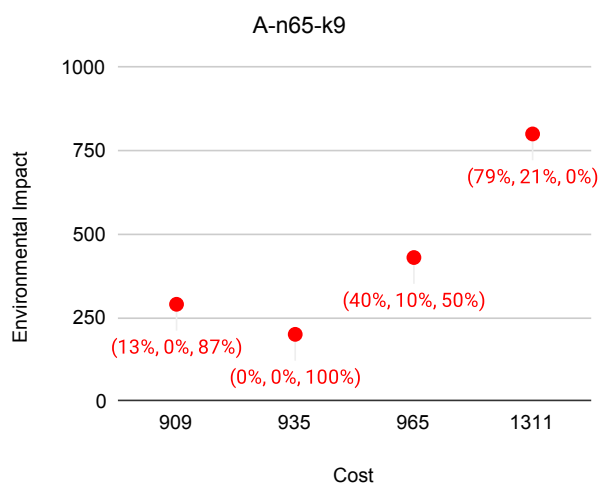

(b) Instance composed of 45 nodes.

Figure 7. Trade-off between environmental and economical costs.

Our second experiment is based on data provided in three studies concerning the ETOP: Panadero et al. [169], Pěnička et al. [183], and Karbowska-Chilinska and Chociej [178]. The decision on selecting these specific articles is based on the fact that they provide similar driving range of the electric vehicles (i.e., the capacity of the batteries employed), as well as similar collected rewards, which are sometimes defined as profits. Although the former addresses a stochastic TOP, the solutions for both the deterministic and the stochastic variants are discussed. In this way, the results regarding the deterministic problem can be directly compared with the ones provided in the latter papers. Accordingly, Figure 8 presents a stacked bar chart with the relationship between the battery capacity and the total collected reward.

In the case of the TOP, the quality of the solutions - in terms of accumulated reward-is directly dependent on the employed batteries, as Figure 8 shows. This behavior is expected, as the larger the battery capacity of a vehicle, the higher the number of locations that the vehicle can feasibly visit. Consequently, it is possible to collect a higher reward amount from them. In contrast, for vehicles with a low battery capacity, it becomes relevant to consider in-route charging operations-which might generate idle times for drivers. For these cases, the operational planning of the routes must be flexible and take into consideration the number of recharging stops that must be completed in order to guarantee the effectiveness of the operation. In the case of tour planning problems, these recharging operations directly affect the waiting time of tourists, which results in sub-optimal solutions for them.

As our third experiment, we have generated new data inspired by a real-world case related to the first months of the COVID-19 crisis in the city of Barcelona (Spain). A group of volunteers offered their home 3D printers to produce items such as face shields, ear savers, and door openers. These items should be collected in each house by a group of volunteer drivers and transported to several consolidation centers. The details of this case study can be found in Tordecilla et al. [184]. Up to 95 nodes (houses) should be visited in the considered instance. This problem is addressed both as an E-TOP and as an E-VRP (if the driving range allows to visit all nodes). Our performed experiment consists in testing 
different values of the driving range-measured in minutes—and analyzing the behavior of the output variables reward, cost, and number of visited nodes. Figure 9 displays the obtained results. The number of visited nodes is provided. When the driving range is 270 min or greater, all nodes are visited. Furthermore, the obtained reward and the incurred cost are provided. Notice that the rise in both variables is steady until the limit of 95 nodes is reached. Thus, a driving range greater than $270 \mathrm{~min}$ does not have any effect in the reward, and leads to a very slight decrease in the cost.

Panadero et al. (2020)

Penicka et al. (2019)

Karbowska-Chilinska and Chociej (2020)

4000

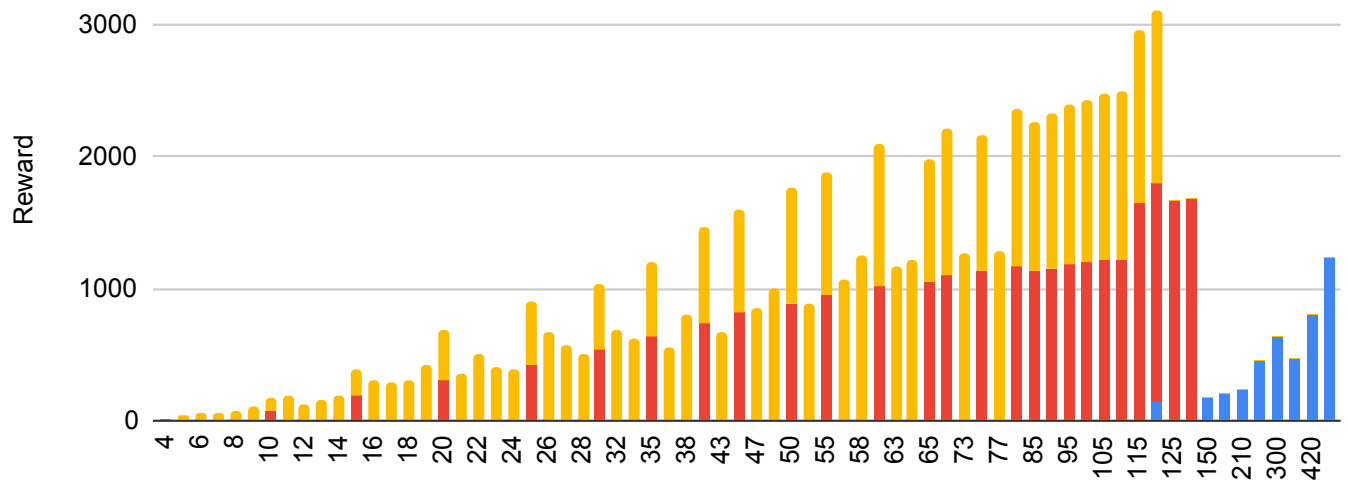

Battery Driving Range (in distance units)

Figure 8. The expected reward (profit/benefit) according to the battery capacity of EVs.

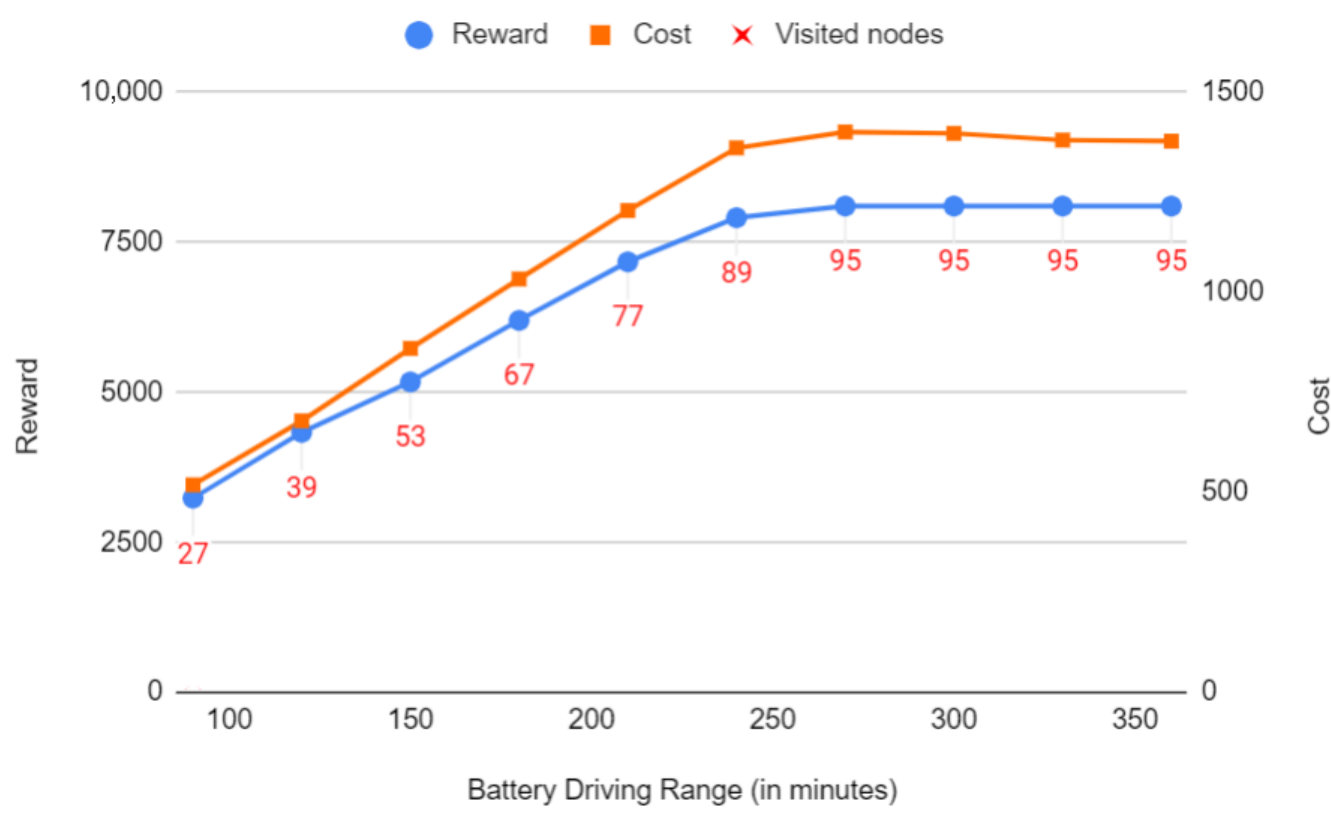

Figure 9. Effect of changing the driving range over three output variables using the E-TOP and E-VRP (if possible).

\section{Conclusions}

This paper has discussed the relevant role of EVs in promoting sustainable transportation activities. It also analyzes how the introduction of vehicles with electric batteries raises new operational challenges due to the inclusion of driving range limitations, long recharging times, scarcity of recharging/swapping stations, and a higher uncertainty on 
the remaining driving capacity. These new characteristics need to be included in different routing optimization models when EVs are considered, but they also represent additional issues in problems that are already difficult to solve. In particular, we review the existing works on electric VRPs, electric ARPs, and electric TOPs, and how different authors have been using alternative approaches to deal with these richer environments. Our review shows that the number of scientific publications on E-ARPs and E-TOPs is much lower than the one corresponding to E-VRPs, which also means that there are many open research lines in the former problems.

Developing efficient algorithms to obtain near-optimal solutions is a critical step in order to promote the generalization of EVs and sustainable transportation practices. Sustainability in transportation and mobility activities can also be promoted by the adoption of horizontal cooperation strategies, the use of telecommunication technology (e.g., Internet of vehicles), new mobility paradigms (e.g., ride-sharing and car-sharing), and the inclusion of externalities in the mathematical models. A series of numerical examples allow us to illustrate how the introduction of driving range limitations can affect the quality of the generated routing plans.

When using electric batteries, the estimation of driving ranges depends on many factors, and several ML models have been proposed. Still, these models are diverse, and there is not a standard framework yet. With the aim of mitigating users' anxiety, manufacturers of electric batteries and EVs are called to develop more sophisticated and accurate models to better estimate the remaining driving ranges.

Recent articles show an increasing interest on integrating real-life characteristics of transportation systems in their optimization models. These include partial recharging, battery swapping, soft time windows, location and probabilistic availability of charging stations, horizontal cooperation strategies, backhauling practices, cost of externalities, random traveling times and customers' demands, traffic conditions, hybrid gas and electric fleets, updated estimates on battery durability, etc. Therefore, simulation-optimization methods, and simheuristics in particular, have become a first-hand tool to generate high-quality routing plans in scenarios under uncertainty. Likewise, as the described characteristics also describe a dynamic environment subject to varying weather or traffic conditions, agile optimization approaches are also required in order to quickly react to changes in the system conditions.

Some of the open research lines identified in our study are (i) the development of statistical and ML models capable of predicting the remaining duration of the batteries according to multiple factors (weather conditions, speed, weight of the vehicle, road and tires condition, etc.); (ii) the proposal of techniques that complement the willingness-to-pay method when estimating the economic cost of transportation externalities; and (iii) the conception of hybrid methodologies that combine optimization algorithms (metaheuristics and matheuristics) with simulation and ML methods, so that electric vehicle routing problems (E-VRPs, E-ARPs, and E-TOPs) can account for dynamic and uncertainty scenarios.

Author Contributions: Conceptualization, A.A.J. and J.F.; methodology, J.C., L.d.C.M., and R.D.T.; writing-original draft preparation, J.C., L.d.C.M., and R.D.T.; writing-review and editing, A.A.J. and J.F. All authors have read and agreed to the published version of the manuscript.

Funding: This research received no external funding.

Institutional Review Board Statement: Not applicable.

Informed Consent Statement: Not applicable.

Data Availability Statement: Not applicable.

Acknowledgments: This work has been partially supported by the Spanish Ministry of Science, Innovation, and Universities (PID2019-111100RB-C21-C22/AEI/10.13039/501100011033, RED2018-102642-T), the SEPIE Erasmus+Program (2019-I-ES01-KA103-062602), and the IoF2020-H2020 (731884) project.

Conflicts of Interest: The authors declare no conflicts of interest. 


\section{References}

1. Ruggieri, R.; Ruggeri, M.; Vinci, G.; Poponi, S. Electric Mobility in a Smart City: European Overview. Energies 2021, 14, 315. [CrossRef]

2. Patella, S.M.; Grazieschi, G.; Gatta, V.; Marcucci, E.; Carrese, S. The Adoption of Green Vehicles in Last Mile Logistics: A Systematic Review. Sustainability 2021, 13, 6. [CrossRef]

3. Hooftman, N.; Messagie, M.; Van Mierlo, J.; Coosemans, T. The Paris Agreement and Zero-Emission Vehicles in Europe: Scenarios for the Road Towards a Decarbonised Passenger Car Fleet. In Towards User-Centric Transport in Europe 2; Springer: Berlin/Heidelberg, Germany, 2020; pp. 151-168.

4. Greene, D.L.; Park, S.; Liu, C. Public policy and the transition to electric drive vehicles in the US: The role of the zero emission vehicles mandates. Energy Strategy Rev. 2014, 5, 66-77. [CrossRef]

5. Masiero, G.; Ogasavara, M.H.; Jussani, A.C.; Risso, M.L. Electric vehicles in China: BYD strategies and government subsidies. Rai Rev. Adm. Inovação 2016, 13, 3-11. [CrossRef]

6. Kapustin, N.O.; Grushevenko, D.A. Long-term electric vehicles outlook and their potential impact on electric grid. Energy Policy 2020, 137, 111103. [CrossRef]

7. Juan, A.A.; Mendez, C.A.; Faulin, J.; De Armas, J.; Grasman, S.E. Electric vehicles in logistics and transportation: A survey on emerging environmental, strategic, and operational challenges. Energies 2016, 9, 86. [CrossRef]

8. Mukherjee, S.C.; Ryan, L. Factors influencing early battery electric vehicle adoption in Ireland. Renew. Sustain. Energy Rev. 2020, 118, 109504. [CrossRef]

9. O'Neill, E.; Moore, D.; Kelleher, L.; Brereton, F. Barriers to electric vehicle uptake in Ireland: Perspectives of car-dealers and policy-makers. Case Stud. Transp. Policy 2019, 7, 118-127. [CrossRef]

10. Beneicke, J.; Juan, A.A.; Xhafa, F.; Lopez-Lopez, D.; Freixes, A. Empowering citizens' cognition and decision making in smart sustainable cities. IEEE Consum. Electron. Mag. 2019, 9, 102-108. [CrossRef]

11. Mor, A.; Speranza, M.G. Vehicle routing problems over time: A survey. 4OR 2020, 1-21. [CrossRef]

12. Simeonova, L.; Wassan, N.; Wassan, N.; Salhi, S. Recent Developments in Real Life Vehicle Routing Problem Applications. In Green Transportation and New Advances in Vehicle Routing Problems; Springer: Berlin/Heidelberg, Germany, 2020; pp. 213-228.

13. Caceres-Cruz, J.; Arias, P.; Guimarans, D.; Riera, D.; Juan, A.A. Rich vehicle routing problem: Survey. ACM Comput. Surv. CSUR 2014, 47, 1-28. [CrossRef]

14. Mourao, M.C.; Pinto, L.S. An updated annotated bibliography on arc routing problems. Networks 2017, 70, 144-194. [CrossRef]

15. Corberan, A.; Eglese, R.; Hasle, G.; Plana, I.; Sanchis, J.M. Arc routing problems: A review of the past, present, and future. Networks 2021, 77, 88-115. [CrossRef]

16. Bayliss, C.; Juan, A.A.; Currie, C.S.; Panadero, J. A learnheuristic approach for the team orienteering problem with aerial drone motion constraints. Appl. Soft Comput. 2020, 92, 106280. [CrossRef]

17. Estrada-Moreno, A.; Ferrer, A.; Juan, A.A.; Panadero, J.; Bagirov, A. The non-smooth and bi-objective team orienteering problem with soft constraints. Mathematics 2020, 8, 1461. [CrossRef]

18. Maier, H.R.; Razavi, S.; Kapelan, Z.; Matott, L.S.; Kasprzyk, J.; Tolson, B.A. Introductory overview: Optimization using evolutionary algorithms and other metaheuristics. Environ. Model. Softw. 2019, 114, 195-213. [CrossRef]

19. Chica, M.; Juan, A.A.; Bayliss, C.; Cordon, O.; Kelton, W.D. Why simheuristics? Benefits, limitations, and best practices when combining metaheuristics with simulation. SORT Stat. Oper. Res. Trans. 2020, 44, 1-24. [CrossRef]

20. Talbi, E.G. Metaheuristics: From Design to Implementation; John Wiley \& Sons: Hoboken, NJ, USA, 2009 ; Volume 74.

21. Elshaer, R.; Awad, H. A taxonomic review of metaheuristic algorithms for solving the vehicle routing problem and its variants. Comput. Ind. Eng. 2020, 140, 106242. [CrossRef]

22. Yu, X.; Gen, M. Introduction to Evolutionary Algorithms; Springer Science \& Business Media: Berlin/Heidelberg, Germany, 2010.

23. Dorigo, M.; Birattari, M.; Stutzle, T. Ant colony optimization. IEEE Comput. Intell. Mag. 2006, 1, 28-39. [CrossRef]

24. MirHassani, S.; Abolghasemi, N. A particle swarm optimization algorithm for open vehicle routing problem. Expert Syst. Appl. 2011, 38, 11547-11551. [CrossRef]

25. Martí, R.; Resende, M.G.; Ribeiro, C.C. Multi-start methods for combinatorial optimization. Eur. J. Oper. Res. 2013, 226, 1-8. [CrossRef]

26. Lourenço, H.R.; Martin, O.C.; Stützle, T. Iterated local search: Framework and applications. In Handbook of Metaheuristics; Springer: Berlin/Heidelberg, Germany, 2010; pp. 363-397.

27. Hansen, P.; Mladenović, N. Variable neighborhood search. In Search Methodologies; Springer: Berlin/Heidelberg, Germany, 2014; pp. 313-337.

28. Williamson, D.P.; Shmoys, D.B. The Design of Approximation Algorithms; Cambridge University Press: Cambridge, UK, 2011.

29. Petersen, P.; Thorgeirsson, A.T.; Scheubner, S.; Otten, S.; Gauterin, F.; Sax, E. Training and Validation Methodology for Range Estimation Algorithms; VEHITS; SciTePress: Crete, Greece, 2019; pp. 434-443.

30. Faulin, J.; Grasman, S.E.; Juan, A.A.; Hirsch, P. Sustainable Transportation: Concepts and Current Practices. In Sustainable Transportation and Smart Logistics; Elsevier: Amsterdam, The Netherlands, 2019; pp. 3-23.

31. McKinnon, A.; Browne, M.; Whiteing, A.; Piecyk, M. Green Logistics: Improving the Environmental Sustainability of Logistics; Kogan Page Publishers: London, UK, 2015.

32. Hensher, D.A.; Button, K.J. Handbook of Transport and the Environment; Elsevier: Amsterdam, The Netherlands, 2003 ; Volume 4. 
33. Sánchez, M.; López-Mosquera, N.; Lera-López, F.; Faulin, J. An extended planned behavior model to explain the willingness to pay to reduce noise pollution in road transportation. J. Clean. Prod. 2018, 177, 144-154. [CrossRef]

34. Lera-López, F.; Faulin, J.; Sánchez, M. Determinants of the willingness-to-pay for reducing the environmental impacts of road transportation. Transp. Res. Part D Transp. Environ. 2012, 17, 215-220. [CrossRef]

35. Denant-Boèmont, L.; Faulin, J.; Hammiche, S.; Serrano-Hernandez, A. Managing transportation externalities in the Pyrenees region: Measuring the willingness-to-pay for road freight noise reduction using an experimental auction mechanism. J. Clean. Prod. 2018, 202, 631-641. [CrossRef]

36. Serrano-Hernández, A.; Faulin, J. Internalizing negative externalities in vehicle routing problems through green taxes and green tolls. SORT 2019, 1, 75-94.

37. Lera-López, F.; Sánchez, M.; Faulin, J.; Cacciolatti, L. Rural environment stakeholders and policy making: Willingness to pay to reduce road transportation pollution impact in the Western Pyrenees. Transp. Res. Part D Transp. Environ. 2014, 32, 129-142. [CrossRef]

38. Dekker, R.; Bloemhof, J.; Mallidis, I. Operations Research for green logistics-An overview of aspects, issues, contributions and challenges. Eur. J. Oper. Res. 2012, 219, 671-679. [CrossRef]

39. Bektaş, T.; Ehmke, J.F.; Psaraftis, H.N.; Puchinger, J. The role of operational research in green freight transportation. Eur. J. Oper. Res. 2019, 274, 807-823. [CrossRef]

40. Panagakos, G. Green corridors basics. In Green Transportation Logistics; Springer: Berlin/Heidelberg, Germany, 2016 ; pp. 81-121.

41. Erdoğan, S.; Miller-Hooks, E. A green vehicle routing problem. Transp. Res. Part E Logist. Transp. Rev. 2012, 48, 100-114. [CrossRef]

42. Ubeda, S.; Arcelus, F.J.; Faulin, J. Green logistics at Eroski: A case study. Int. J. Prod. Econ. 2011, 131, 44-51. [CrossRef]

43. Lin, C.; Choy, K.L.; Ho, G.T.; Chung, S.H.; Lam, H. Survey of green vehicle routing problem: Past and future trends. Expert Syst. Appl. 2014, 41, 1118-1138. [CrossRef]

44. Ren, R.; Hu, W.; Dong, J.; Sun, B.; Chen, Y.; Chen, Z. A systematic literature review of green and sustainable logistics: Bibliometric analysis, research trend and knowledge taxonomy. Int. J. Environ. Res. Public Health 2020, 17, 261. [CrossRef]

45. Moghdani, R.; Salimifard, K.; Demir, E.; Benyettou, A. The green vehicle routing problem: A systematic literature review. J. Clean. Prod. 2020, 279, 123691. [CrossRef]

46. Asghari, M.; Mirzapour Al-e-hashem, S.M.J. Green vehicle routing problem: A state-of-the-art review. Int. J. Prod. Econ. 2020, 231, 107899. [CrossRef]

47. Sawik, B.; Faulin, J.; Pérez-Bernabeu, E. Multi-criteria optimization for fleet size with environmental aspects. Transp. Res. Procedia 2017, 27, 61-68. [CrossRef]

48. Serrano-Hernández, A.; Juan, A.A.; Faulin, J.; Perez-Bernabeu, E. Horizontal collaboration in freight transport: Concepts, benefits and environmental challenges. SORT 2017, 1, 393-414.

49. Serrano-Hernandez, A.; Faulin, J.; Hirsch, P.; Fikar, C. Agent-based simulation for horizontal cooperation in logistics and transportation: From the individual to the grand coalition. Simul. Model. Pract. Theory 2018, 85, 47-59. [CrossRef]

50. Quintero-Araujo, C.L.; Gruler, A.; Juan, A.A.; Faulin, J. Using horizontal cooperation concepts in integrated routing and facility-location decisions. Int. Trans. Oper. Res. 2019, 26, 551-576. [CrossRef]

51. Santos, M.J.; Amorim, P.; Marques, A.; Carvalho, A.; Póvoa, A. The vehicle routing problem with backhauls towards a sustainability perspective: A review. TOP 2019, 28, 358-401. [CrossRef]

52. Belloso, J.; Juan, A.A.; Faulin, J. An iterative biased-randomized heuristic for the fleet size and mix vehicle-routing problem with backhauls. Int. Trans. Oper. Res. 2019, 26, 289-301. [CrossRef]

53. Serrano-Hernandez, A.; de la Torre, R.; Cadarso, L.; Faulin, J. Urban e-Grocery Distribution Design in Pamplona (Spain) Applying an Agent-Based Simulation Model with Horizontal Cooperation Scenarios. Algorithms 2021, 14, 20. [CrossRef]

54. Archetti, C.; Savelsbergh, M.; Speranza, M.G. The vehicle routing problem with occasional drivers. Eur. J. Oper. Res. 2016, 254, 472-480. [CrossRef]

55. Sampaio, A.; Savelsbergh, M.; Veelenturf, L.; Van Woensel, T. Crowd-based city logistics. In Sustainable Transportation and Smart Logistics; Elsevier: Amsterdam, The Netherlands, 2019; pp. 381-400.

56. McKinnon, A. Crowdshipping: A Communal Approach to Reducing Urban Traffic Levels? Kühne Logistics University: Hamburg, Germany, 2016.

57. Lloyd, J.; McCarney, S.; Ouhichi, R.; Lydon, P.; Zaffran, M. Optimizing energy for a 'green' vaccine supply chain. Vaccine 2015, 33, 908-913. [CrossRef]

58. Kuo, J.C.; Chen, M.C. Developing an advanced multi-temperature joint distribution system for the food cold chain. Food Control 2010, 21, 559-566. [CrossRef]

59. Mercier, S.; Villeneuve, S.; Mondor, M.; Uysal, I. Time-temperature management along the food cold chain: A review of recent developments. Compr. Rev. Food Sci. Food Saf. 2017, 16, 647-667. [CrossRef] [PubMed]

60. Deloison, T.; Hannon, E.; Huber, A.; Heid, B.; Klink, C.; Sahay, R.; Wolff, C. The Future of the Last-Mile Ecosystem; World Economic Forum: Geneva, Switzerland; 2020.

61. Ostermeier, M.; Heimfarth, A.; Hübner, A. Cost-optimal truck-and-robot routing for last-mile delivery. Networks 2021, 1-26. [CrossRef] 
62. Del Vecchio, P.; Secundo, G.; Maruccia, Y.; Passiante, G. A system dynamic approach for the smart mobility of people: Implications in the age of big data. Technol. Forecast. Soc. Chang. 2019, 149, 119771. [CrossRef]

63. Roumboutsos, A.; Kapros, S.; Vanelslander, T. Green city logistics: Systems of Innovation to assess the potential of E-vehicles. Res. Transp. Bus. Manag. 2014, 11, 43-52. [CrossRef]

64. Demir, E.; Bektaş, T.; Laporte, G. A review of recent research on green road freight transportation. Eur. J. Oper. Res. 2014, 237, 775-793. [CrossRef]

65. Meyer, T. Decarbonizing road freight transportation-A bibliometric and network analysis. Transp. Res. Part D Transp. Environ. 2020, 89, 102619. [CrossRef]

66. Ehrler, V.C.; Schöder, D.; Seidel, S. Challenges and perspectives for the use of electric vehicles for last mile logistics of grocery e-commerce-Findings from case studies in Germany. Res. Transp. Econ. 2019, 87, 100757. [CrossRef]

67. Muñoz-Villamizar, A.; Montoya-Torres, J.R.; Faulin, J. Impact of the use of electric vehicles in collaborative urban transport networks: A case study. Transp. Res. Part D Transp. Environ. 2017, 50, 40-54. [CrossRef]

68. Catenacci, M.; Fiorese, G.; Verdolini, E.; Bosetti, V. Going electric: Expert survey on the future of battery technologies for electric vehicles. In Innovation under Uncertainty; Edward Elgar Publishing: Cheltenham, UK, 2015.

69. Vaz, W.; Nandi, A.K.; Landers, R.G.; Koylu, U.O. Electric vehicle range prediction for constant speed trip using multi-objective optimization. J. Power Sources 2015, 275, 435-446. [CrossRef]

70. Zhou, Y.; Wen, R.; Wang, H.; Cai, H. Optimal battery electric vehicles range: A study considering heterogeneous travel patterns, charging behaviors, and access to charging infrastructure. Energy 2020, 197, 116945. [CrossRef]

71. Funke, S.Á.; Sprei, F.; Gnann, T.; Plötz, P. How much charging infrastructure do electric vehicles need? A review of the evidence and international comparison. Transp. Res. Part D Transp. Environ. 2019, 77, 224-242. [CrossRef]

72. Baek, D.; Chen, Y.; Bocca, A.; Bottaccioli, L.; Di Cataldo, S.; Gatteschi, V.; Pagliari, D.J.; Patti, E.; Urgese, G.; Chang, N.; et al. Battery-aware operation range estimation for terrestrial and aerial electric vehicles. IEEE Trans. Veh. Technol. 2019, 68, 5471-5482. [CrossRef]

73. Kim, S.; Lee, J.; Lee, C. Does driving range of electric vehicles influence electric vehicle adoption? Sustainability 2017,9 , 1783. [CrossRef]

74. Malik, M.; Dincer, I.; Rosen, M.A. Review on use of phase change materials in battery thermal management for electric and hybrid electric vehicles. Int. J. Energy Res. 2016, 40, 1011-1031. [CrossRef]

75. Liu, K.; Li, K.; Peng, Q.; Zhang, C. A brief review on key technologies in the battery management system of electric vehicles. Front. Mech. Eng. 2019, 14, 47-64. [CrossRef]

76. Lipu, M.H.; Hannan, M.; Karim, T.F.; Hussain, A.; Saad, M.H.; Ayob, A.; Miah, M.S.; Mahlia, T. Intelligent algorithms and control strategies for battery management system in electric vehicles: Progress, challenges and future outlook. J. Clean. Prod. 2021, 292, 126044. [CrossRef]

77. Shi, X.; Pan, J.; Wang, H.; Cai, H. Battery electric vehicles: What is the minimum range required? Energy 2019, 166, 352-358. [CrossRef]

78. Bi, J.; Wang, Y.; Shao, S.; Cheng, Y. Residual range estimation for battery electric vehicle based on radial basis function neural network. Measurement 2018, 128, 197-203. [CrossRef]

79. Bi, J.; Wang, Y.; Sai, Q.; Ding, C. Estimating remaining driving range of battery electric vehicles based on real-world data: A case study of Beijing, China. Energy 2019, 169, 833-843. [CrossRef]

80. Fetene, G.M.; Kaplan, S.; Mabit, S.L.; Jensen, A.F.; Prato, C.G. Harnessing big data for estimating the energy consumption and driving range of electric vehicles. Transp. Res. Part D Transp. Environ. 2017, 54, 1-11. [CrossRef]

81. Fiori, C.; Ahn, K.; Rakha, H.A. Optimum routing of battery electric vehicles: Insights using empirical data and microsimulation. Transp. Res. Part D Transp. Environ. 2018, 64, 262-272. [CrossRef]

82. Kempton, W. Electric vehicles: Driving range. Nat. Energy 2016, 1, 1-2. [CrossRef]

83. Neaimeh, M.; Hill, G.A.; Hübner, Y.; Blythe, P.T. Routing systems to extend the driving range of electric vehicles. IET Intell. Transp. Syst. 2013, 7, 327-336. [CrossRef]

84. Sautermeister, S.; Ott, F.; Vaillant, M.; Gauterin, F. Reducing range estimation uncertainty with a hybrid powertrain model and online parameter estimation. In Proceedings of the 2017 IEEE 20th International Conference on Intelligent Transportation Systems (ITSC), Yokohama, Japan, 16-19 October 2017; IEEE: New York, NY, USA, 2017; pp. 1-6.

85. Zhao, L.; Yao, W.; Wang, Y.; Hu, J. Machine Learning-Based Method for Remaining Range Prediction of Electric Vehicles. IEEE Access 2020, 8, 212423-212441. [CrossRef]

86. Zheng, B.; He, P.; Zhao, L.; Li, H. A hybrid machine learning model for range estimation of electric vehicles. In Proceedings of the 2016 IEEE Global Communications Conference (GLOBECOM), Washington, DC, USA, 4-8 December 2016; IEEE: New York, NY, USA, 2016; pp. 1-6.

87. Thorgeirsson, A.T.; Vaillant, M.; Scheubner, S.; Gauterin, F. Evaluating system architectures for driving range estimation and charge planning for electric vehicles. Softw. Pract. Exp. 2021, 51, 72-90. [CrossRef]

88. Ghorbani, E.; Alinaghian, M.; Gharehpetian, G.; Mohammadi, S.; Perboli, G.; A Survey on Environmentally Friendly Vehicle Routing Problem and a Proposal of Its Classification. Sustainability 2020, 12, 9079. [CrossRef]

89. Lin, J.; Zhou, W.; Wolfson, O. Electric vehicle routing problem. Transp. Res. Procedia 2016, 12, 508-521. [CrossRef] 
90. Conrad, R.G.; Figliozzi, M.A. The recharging vehicle routing problem. In Proceedings of the 2011 Industrial Engineering Research Conference, IISE, Reno, NV, USA, 2011; p. 8.

91. Juan, A.A.; Goentzel, J.; Bektaş, T. Routing fleets with multiple driving ranges: Is it possible to use greener fleet configurations? Appl. Soft Comput. 2014, 21, 84-94. [CrossRef]

92. Dominguez, O.; Juan, A.A.; Faulin, J. A biased-randomized algorithm for the two-dimensional vehicle routing problem with and without item rotations. Int. Trans. Oper. Res. 2014, 21, 375-398. [CrossRef]

93. Quintero-Araujo, C.L.; Caballero-Villalobos, J.P.; Juan, A.A.; Montoya-Torres, J.R. A biased-randomized metaheuristic for the capacitated location routing problem. Int. Trans. Oper. Res. 2017, 24, 1079-1098. [CrossRef]

94. Afroditi, A.; Boile, M.; Theofanis, S.; Sdoukopoulos, E.; Margaritis, D. Electric vehicle routing problem with industry constraints: Trends and insights for future research. Transp. Res. Procedia 2014, 3, 452-459. [CrossRef]

95. Schneider, M.; Stenger, A.; Goeke, D. The electric vehicle-routing problem with time windows and recharging stations. Transp. Sci. 2014, 48, 500-520. [CrossRef]

96. Schiffer, M.; Walther, G. The electric location routing problem with time windows and partial recharging. Eur. J. Oper. Res. 2017, 260, 995-1013. [CrossRef]

97. Zhou, Y.; Chen, L.; Yang, Y.; Li, Y.; Cheng, G.; Fu, Y.; Zhu, C.; Liu, Y.; Mao, H. Electric vehicle routing problem: Model and algorithm. In Proceedings of the 2020 12th International Conference on Measuring Technology and Mechatronics Automation (ICMTMA), Phuket, Thailand, 28-29 February 2020; IEEE: New York, NY, USA, 2020; pp. 1049-1054.

98. Erdelić, T.; Carić, T. A survey on the electric vehicle routing problem: Variants and solution approaches. J. Adv. Transp. 2019, 2019, 5075671 . [CrossRef]

99. Li, H.; Li, Z.; Cao, L.; Wang, R.; Ren, M. Research on Optimization of Electric Vehicle Routing Problem with Time Window. IEEE Access 2020, 8, 146707-146718. [CrossRef]

100. Zhao, C.; Shi, H. Large-Scale Electric Vehicle Route Optimization Based on Adaptive Variable Neighborhood Search. Huadong Ligong Daxue Xuebao J. East China Univ. Sci. Technol. 2020, 46, 694-701.

101. Zhu, Y.; Lee, K.; Wang, Y. Adaptive Elitist Genetic Algorithm with Improved Neighbor Routing Initialization for Electric Vehicle Routing Problems. IEEE Access 2021, 9, 16661-16671. [CrossRef]

102. Outalha, A.; Lakhal, Y.; Baghli, F.; Kzaiber, F. Electric vehicle routing problem using timed Petri nets and optimization algorithm. J. Adv. Res. Dyn. Control Syst. 2020, 12, 1109-1115. [CrossRef]

103. Li, Y.; Lim, M.; Tan, Y.; Lee, S.; Tseng, M.L. Sharing economy to improve routing for urban logistics distribution using electric vehicles. Resour. Conserv. Recycl. 2020, 153, 104585. [CrossRef]

104. Zhang, S.; Chen, M.; Zhang, W.; Zhuang, X. Fuzzy optimization model for electric vehicle routing problem with time windows and recharging stations. Expert Syst. Appl. 2020, 145, 113123. [CrossRef]

105. Zhen, L.; Xu, Z.; Ma, C.; Xiao, L. Hybrid electric vehicle routing problem with mode selection. Int. J. Prod. Res. 2020, 58, 562-576. [CrossRef]

106. Keskin, M.; Çatay, B.; Laporte, G. A simulation-based heuristic for the electric vehicle routing problem with time windows and stochastic waiting times at recharging stations. Comput. Oper. Res. 2021, 125, 105060. [CrossRef]

107. Bahrami, S.; Nourinejad, M.; Amirjamshidi, G.; Roorda, M. The Plugin Hybrid Electric Vehicle routing problem: A powermanagement strategy model. Transp. Res. Part C: Emerg. Technol. 2020, 111, 318-333. [CrossRef]

108. Zhu, X.; Yan, R.; Huang, Z.; Wei, W.; Yang, J.; Kudratova, S. Logistic Optimization for Multi Depots Loading Capacitated Electric Vehicle Routing Problem from Low Carbon Perspective. IEEE Access 2020, 8, 31934-31947. [CrossRef]

109. Kancharla, S.R.; Ramadurai, G. Electric vehicle routing problem with non-linear charging and load-dependent discharging. Expert Syst. Appl. 2020, 160, 113714. [CrossRef]

110. Mao, H.; Shi, J.; Zhou, Y.; Zhang, G. The Electric Vehicle Routing Problem With Time Windows and Multiple Recharging Options. IEEE Access 2020, 8, 114864-114875. [CrossRef]

111. Lu, J.; Chen, Y.; Hao, J.K.; He, R. The Time-dependent Electric Vehicle Routing Problem: Model and solution. Expert Syst. Appl. 2020, 161, 113593. [CrossRef]

112. Raeesi, R.; Zografos, K.G. The electric vehicle routing problem with time windows and synchronised mobile battery swapping. Transp. Res. Part B Methodol. 2020, 140, 101-129. [CrossRef]

113. Li, X.; Shi, X.; Zhao, Y.; Liang, H.; Dong, Y. SVND enhanced metaheuristic for plug-in hybrid electric vehicle routing problem. Appl. Sci. 2020, 10, 441. [CrossRef]

114. Karakatič, S. Optimizing nonlinear charging times of electric vehicle routing with genetic algorithm. Expert Syst. Appl. 2021, 164, 114039. [CrossRef]

115. Li, J.; Wang, F.; He, Y. Electric vehicle routing problem with battery swapping considering energy consumption and carbon emissions. Sustainability 2020, 12, 10537. [CrossRef]

116. Granada-Echeverri, M.; Cubides, L.; Bustamante, J. The electric vehicle routing problem with backuals. Int. J. Ind. Eng. Comput. 2020, 11, 131-152.

117. Löffler, M.; Desaulniers, G.; Irnich, S.; Schneider, M. Routing electric vehicles with a single recharge per route. Networks 2020, 76, 187-205. [CrossRef]

118. Lee, C. An exact algorithm for the electric-vehicle routing problem with nonlinear charging time. J. Oper. Res. Soc. 2020, 72, 1461-1485. [CrossRef] 
119. Al Theeb, N.; Hayajneh, M.; AL Qubelat, N. Optimization of logistic plans with adopting the green technology considerations by utilizing electric vehicle routing problem. Ind. Eng. Manag. Syst. 2021, 19, 774-789.

120. Lin, J.; Zhou, W. Important factors to daily vehicle routing cost of battery electric delivery trucks. Int. J. Sustain. Transp. 2021, 15, 541-558. [CrossRef]

121. Taş, D. Electric vehicle routing with flexible time windows: A column generation solution approach. Transp. Lett. 2021, 13, 97-103. [CrossRef]

122. Zhao, Z.X.; Li, X.M. Electric Vehicle Route Optimization for Fresh Logistics Distribution Based on Time-varying Traffic Congestion. Jiaotong Yunshu Xitong Gongcheng Yu Xinxi J. Transp. Syst. Eng. Inf. Technol. 2020, 20, 218-225.

123. Hulagu, S.; Celikoglu, H. An electric vehicle routing problem with intermediate nodes for shuttle fleets. IEEE Trans. Intell. Transp. Syst. 2020, 1-13. [CrossRef]

124. Zhao, Z.; Li, X.; Zhou, X. Distribution route optimization for electric vehicles in urban cold chain logistics for fresh products under time-varying traffic conditions. Math. Probl. Eng. 2020, 2020, 9864935. [CrossRef]

125. Yang, S.; Ning, L.; Tong, L.; Shang, P. Optimizing electric vehicle routing problems with mixed backhauls and recharging strategies in multi-dimensional representation network. Expert Syst. Appl. 2021, 176, 114804. [CrossRef]

126. Bac, U.; Erdem, M. Optimization of electric vehicle recharge schedule and routing problem with time windows and partial recharge: A comparative study for an urban logistics fleet. Sustain. Cities Soc. 2021, 70, 102883. [CrossRef]

127. Yu, V.; Jodiawan, P.; Gunawan, A. An Adaptive Large Neighborhood Search for the green mixed fleet vehicle routing problem with realistic energy consumption and partial recharges. Appl. Soft Comput. 2021, 105, 107251. [CrossRef]

128. Li, D.; Chen, Y.; Zhang, Z. A branch-and-price algorithm for electric vehicle routing problem with time windows and mixed fleet. Xitong Gongcheng Lilun Yu Shijian Syst. Eng. Theory Pract. 2021, 41, 995-1009.

129. Yindong, S.; Liwen, P.; Jingpeng, L. An improved estimation of distribution algorithm for multi-compartment electric vehicle routing problem. J. Syst. Eng. Electron. 2021, 32, 365-379. [CrossRef]

130. Basso, R.; Kulcsár, B.; Sanchez-Diaz, I. Electric vehicle routing problem with machine learning for energy prediction. Transp. Res. Part B Methodol. 2021, 145, 24-55. [CrossRef]

131. Jia, Y.; Mei, Y.; Zhang, M. A Bilevel Ant Colony Optimization Algorithm for Capacitated Electric Vehicle Routing Problem. IEEE Trans. Cybern. 2021, 1-14. [CrossRef]

132. Wang, N.; Sun, Y.; Wang, H. An Adaptive Memetic Algorithm for Dynamic Electric Vehicle Routing Problem with Time-Varying Demands. Math. Probl. Eng. 2021, 2021, 6635749.

133. Deng, J.; Li, J.; Li, C.; Han, Y.; Liu, Q.; Niu, B.; Liu, L.; Zhang, B. A hybrid algorithm for electric vehicle routing problem with nonlinear charging. J. Intell. Fuzzy Syst. 2021, 40, 5383-5402. [CrossRef]

134. Ham, A.; Park, M.J. Electric vehicle route optimization under time-of-use electricity pricing. IEEE Access 2021, 9, 37220-37228. [CrossRef]

135. Florio, A.; Absi, N.; Feillet, D. Routing electric vehicles on congested street networks. Transp. Sci. 2021, 55, 238-256. [CrossRef]

136. Park, H.; Jin, S. Electric Vehicle Routing Problem with Heterogeneous Vehicles and Partial Charge. Int. J. Ind. Eng. Manag. 2020, 11, 215-225. [CrossRef]

137. Ferro, G.; Paolucci, M.; Robba, M. Optimal Charging and Routing of Electric Vehicles with Power Constraints and Time-of-Use Energy Prices. IEEE Trans. Veh. Technol. 2020, 69, 14436-14447. [CrossRef]

138. Ge, X.; Zhu, Z.; Jin, Y. Electric Vehicle Routing Problems with Stochastic Demands and Dynamic Remedial Measures. Math. Probl. Eng. 2020, 2020, 1-15.

139. Wang, L.; Gao, S.; Wang, K.; Li, T.; Li, L.; Chen, Z. Time-Dependent Electric Vehicle Routing Problem with Time Windows and Path Flexibility. J. Adv. Transp. 2020, 2020, 3030197. [CrossRef]

140. Keskin, M.; Çatay, B. Partial recharge strategies for the electric vehicle routing problem with time windows. Transp. Res. Part $C$ Emerg. Technol. 2016, 65, 111-127. [CrossRef]

141. Verma, A. Electric vehicle routing problem with time windows, recharging stations and battery swapping stations. EURO J. Transp. Logist. 2018, 7, 415-451. [CrossRef]

142. Zhao, M.; Lu, Y. A heuristic approach for a real-world electric vehicle routing problem. Algorithms 2019, 12, 45. [CrossRef]

143. Eskandarpour, M.; Ouelhadj, D.; Hatami, S.; Juan, A.A.; Khosravi, B. Enhanced multi-directional local search for the bi-objective heterogeneous vehicle routing problem with multiple driving ranges. Eur. J. Oper. Res. 2019, 277, 479-491. [CrossRef]

144. Hatami, S.; Eskandarpour, M.; Chica, M.; Juan, A.A.; Ouelhadj, D. Green hybrid fleets using electric vehicles: Solving the heterogeneous vehicle routing problem with multiple driving ranges and loading capacities. SORT Stat. Oper. Res. Trans. 2020, $44,141-170$.

145. Hiermann, G.; Puchinger, J.; Ropke, S.; Hartl, R.F. The electric fleet size and mix vehicle routing problem with time windows and recharging stations. Eur. J. Oper. Res. 2016, 252, 995-1018. [CrossRef]

146. Cussigh, M.; Löchel, C.; Straub, T.; Hamacher, T. Assessing Time-Optimal Journeys: Combined Routing, Charging and Velocity Strategies for Electric Vehicles. In Proceedings of the 2020 Forum on Integrated and Sustainable Transportation Systems (FISTS), Delft, The Netherlands, 3-5 November 2020; IEEE: New York, NY, USA, 2020; pp. 51-57.

147. Desaulniers, G.; Errico, F.; Irnich, S.; Schneider, M. Exact algorithms for electric vehicle-routing problems with time windows. Oper. Res. 2016, 64, 1388-1405. [CrossRef] 
148. Sweda, T.M.; Dolinskaya, I.S.; Klabjan, D. Adaptive routing and recharging policies for electric vehicles. Transp. Sci. 2017, 51, 1326-1348. [CrossRef]

149. Froger, A.; Mendoza, J.E.; Jabali, O.; Laporte, G. A Matheuristic for the Electric Vehicle Routing Problem with Capacitated Charging Stations. Ph.D. Thesis, Centre Interuniversitaire de Recherche Sur Les Reseaux D'entreprise, Montreal, QC, Canada, 2017.

150. Montoya, A.; Guéret, C.; Mendoza, J.E.; Villegas, J.G. The electric vehicle routing problem with nonlinear charging function. Transp. Res. Part B Methodol. 2017, 103, 87-110. [CrossRef]

151. Caggiani, L.; Colovic, A.; Prencipe, L.P.; Ottomanelli, M. A green logistics solution for last-mile deliveries considering e-vans and e-cargo bikes. Transp. Res. Procedia 2021, 52, 75-82. [CrossRef]

152. Yurtseven, C.; Gökçe, M.A. A Novel Arc-routing Problem of Electric Powered Street Sweepers with Time Windows and Intermediate Stops. IFAC-PapersOnLine 2019, 52, 2308-2313. [CrossRef]

153. Campbell, J.F.; Corberán, Á.; Plana, I.; Sanchis, J.M.; Segura, P. Solving the length constrained K-drones rural postman problem. Eur. J. Oper. Res. 2020, 292, 60-72. [CrossRef]

154. Campbell, J.F.; Corberán, Á.; Plana, I.; Sanchis, J.M. Drone arc routing problems. Networks 2018, 72, 543-559. [CrossRef]

155. Chow, J.Y. Dynamic UAV-based traffic monitoring under uncertainty as a stochastic arc-inventory routing policy. Int. J. Transp. Sci. Technol. 2016, 5, 167-185. [CrossRef]

156. Li, M.; Zhen, L.; Wang, S.; Lv, W.; Qu, X. Unmanned aerial vehicle scheduling problem for traffic monitoring. Comput. Ind. Eng. 2018, 122, 15-23. [CrossRef]

157. Liu, Y.; Shi, J.; Liu, Z.; Huang, J.; Zhou, T. Two-layer routing for high-voltage powerline inspection by cooperated ground vehicle and drone. Energies 2019, 12, 1385. [CrossRef]

158. Luo, H.; Zhang, P.; Wang, J.; Wang, G.; Meng, F. Traffic patrolling routing problem with drones in an urban road system. Sensors 2019, 19, 5164. [CrossRef]

159. Poikonen, S.; Campbell, J.F. Future directions in drone routing research. Networks 2021, 77, 116-126. [CrossRef]

160. Donateo, T.; Ficarella, A.; Spedicato, L.; Arista, A.; Ferraro, M. A new approach to calculating endurance in electric flight and comparing fuel cells and batteries. Appl. Energy 2017, 187, 807-819. [CrossRef]

161. Fotouhi, A.; Qiang, H.; Ding, M.; Hassan, M.; Giordano, L.G.; Garcia-Rodriguez, A.; Yuan, J. Survey on UAV cellular communications: Practical aspects, standardization advancements, regulation, and security challenges. IEEE Commun. Surv. Tutor. 2019, 21, 3417-3442. [CrossRef]

162. Mozaffari, M.; Saad, W.; Bennis, M.; Nam, Y.H.; Debbah, M. A tutorial on UAVs for wireless networks: Applications, challenges, and open problems. IEEE Commun. Surv. Tutor. 2019, 21, 2334-2360. [CrossRef]

163. De Armas, J.; Keenan, P.; Juan, A.A.; McGarraghy, S. Solving large-scale time capacitated arc routing problems: From real-time heuristics to metaheuristics. Ann. Oper. Res. 2019, 273, 135-162. [CrossRef]

164. Gonzalez-Martin, S.; Juan, A.A.; Riera, D.; Elizondo, M.G.; Ramos, J.J. A simheuristic algorithm for solving the arc routing problem with stochastic demands. J. Simul. 2018, 12, 53-66. [CrossRef]

165. Chao, I.M.; Golden, B.L.; Wasil, E.A. The team orienteering problem. Eur. J. Oper. Res. 1996, 88, 464-474. [CrossRef]

166. Reyes-Rubiano, L.S.; Ospina-Trujillo, C.F.; Faulin, J.; Mozos, J.M.; Panadero, J.; Juan, A.A. The team orienteering problem with stochastic service times and driving-range limitations: A simheuristic approach. In Proceedings of the 2018 Winter Simulation Conference (WSC), Gothenburg, Sweden, 9-12 December 2018; IEEE: New York, NY, USA, 2018; pp. 3025-3035.

167. Liao, C.S.; Lu, S.H.; Shen, Z.J.M. The electric vehicle touring problem. Transp. Res. Part B Methodol. 2016, 86, 163-180. [CrossRef]

168. Mufalli, F.; Batta, R.; Nagi, R. Simultaneous sensor selection and routing of unmanned aerial vehicles for complex mission plans. Comput. Oper. Res. 2012, 39, 2787-2799. [CrossRef]

169. Panadero, J.; Juan, A.A.; Bayliss, C.; Currie, C. Maximising reward from a team of surveillance drones: A simheuristic approach to the stochastic team orienteering problem. Eur. J. Ind. Eng. 2020, 14, 485-516. [CrossRef]

170. Juan, A.A.; Freixes, A.; Panadero, J.; Serrat, C.; Estrada-Moreno, A. Routing Drones in Smart Cities: A Biased-Randomized Algorithm for Solving the Team Orienteering Problem in Real Time. Transp. Res. Procedia 2020, 47, 243-250. [CrossRef]

171. Martins, L.d.C.; Hirsch, P.; Juan, A.A. Agile optimization of a two-echelon vehicle routing problem with pickup and delivery. Int. Trans. Oper. Res. 2021, 28, 201-221. [CrossRef]

172. Martins, L.d.C.; de la Torre, R.; Corlu, C.G.; Juan, A.A.; Masmoudi, M.A. Optimizing ride-sharing operations in smart sustainable cities: Challenges and the need for agile algorithms. Comput. Ind. Eng. 2021, 153, 107080. [CrossRef]

173. Arnau, Q.; Juan, A.A.; Serra, I. On the use of learnheuristics in vehicle routing optimization problems with dynamic inputs. Algorithms 2018, 11, 208. [CrossRef]

174. Saeedvand, S.; Aghdasi, H.S.; Baltes, J. Novel hybrid algorithm for Team Orienteering Problem with Time Windows for rescue applications. Appl. Soft Comput. 2020, 96, 106700. [CrossRef]

175. Xu, W.; Xu, Z.; Peng, J.; Liang, W.; Liu, T.; Jia, X.; Das, S.K. Approximation algorithms for the team orienteering problem. In Proceedings of the IEEE INFOCOM 2020-IEEE Conference on Computer Communications, Toronto, ON, Canada, 6-9 July 2020; IEEE: New York, NY, USA, 2020; pp. 1389-1398.

176. Sundar, K.; Sanjeevi, S. A Branch-and-Price Algorithm for a Team Orienteering Problem for Fixed-Wing Drones. arXiv 2021, arXiv:1912.04353.

177. Gavalas, D.; Konstantopoulos, C.; Mastakas, K.; Pantziou, G. A survey on algorithmic approaches for solving tourist trip design problems. J. Heuristics 2014, 20, 291-328. [CrossRef] 
178. Karbowska-Chilinska, J.; Chociej, K. Genetic Algorithm for Generation Multistage Tourist Route of Electrical Vehicle. In Proceedings of the International Conference on Computer Information Systems and Industrial Management, Bialystok, Poland, 16-18 October 2020; Springer: Berlin/Heidelberg, Germany, 2020; pp. 366-376.

179. Lee, J.; Park, G.L. Orienteering problem modeling for electric vehicle-based tour. In Proceedings of the Asian Conference on Intelligent Information and Database Systems, Kuala Lumpur, Malaysia, 18-20 March 2013; Springer: Berlin/Heidelberg, Germany, 2013; pp. 100-108.

180. Lee, J.; Kim, S.W.; Park, G.L. A tour recommendation service for electric vehicles based on a hybrid orienteering model. In Proceedings of the 28th Annual ACM Symposium on Applied Computing, Coimbra, Portugal, 18-22 March 2013; pp. 1652-1654.

181. Wang, Y.W.; Lin, C.C.; Lee, T.J. Electric vehicle tour planning. Transp. Res. Part D Transp. Environ. 2018, 63, 121-136. [CrossRef]

182. Chen, R.; Liu, X.; Miao, L.; Yang, P. Electric Vehicle Tour Planning Considering Range Anxiety. Sustainability 2020, $12,3685$. 
[CrossRef]

183. Pěnička, R.; Faigl, J.; Saska, M.; Váňa, P. Data collection planning with non-zero sensing distance for a budget and curvature constrained unmanned aerial vehicle. Auton. Robot. 2019, 43, 1937-1956. [CrossRef]

184. Tordecilla, R.D.; Martins, L.d.C.; Saiz, M.; Copado-Mendez, P.J.; Panadero, J.; Juan, A.A. Agile Computational Intelligence for Supporting Hospital Logistics During the COVID-19 Crisis. In Computational Management; Springer: Berlin/Heidelberg, Germany, 2021; pp. 383-407. 